\section{ECOHFTOR}

Make Your Publications Visible.
A Service of

フBUW

Jayet, Hubert; Marchal, Léa

\title{
Working Paper \\ Migration and FDI: Reconciling the standard trade theory with empirical evidence
}

Kiel Working Paper, No. 2039

Provided in Cooperation with:

Kiel Institute for the World Economy (IfW)

Suggested Citation: Jayet, Hubert; Marchal, Léa (2016) : Migration and FDI: Reconciling the standard trade theory with empirical evidence, Kiel Working Paper, No. 2039, Kiel Institute for the World Economy (IfW), Kiel

This Version is available at:

http://hdl.handle.net/10419/140903

\section{Standard-Nutzungsbedingungen:}

Die Dokumente auf EconStor dürfen zu eigenen wissenschaftlichen Zwecken und zum Privatgebrauch gespeichert und kopiert werden.

Sie dürfen die Dokumente nicht für öffentliche oder kommerzielle Zwecke vervielfältigen, öffentlich ausstellen, öffentlich zugänglich machen, vertreiben oder anderweitig nutzen.

Sofern die Verfasser die Dokumente unter Open-Content-Lizenzen (insbesondere CC-Lizenzen) zur Verfügung gestellt haben sollten, gelten abweichend von diesen Nutzungsbedingungen die in der dort genannten Lizenz gewährten Nutzungsrechte.
Terms of use:

Documents in EconStor may be saved and copied for your personal and scholarly purposes.

You are not to copy documents for public or commercial purposes, to exhibit the documents publicly, to make them publicly available on the internet, or to distribute or otherwise use the documents in public.

If the documents have been made available under an Open Content Licence (especially Creative Commons Licences), you may exercise further usage rights as specified in the indicated licence. 


\title{
Working Papers
}

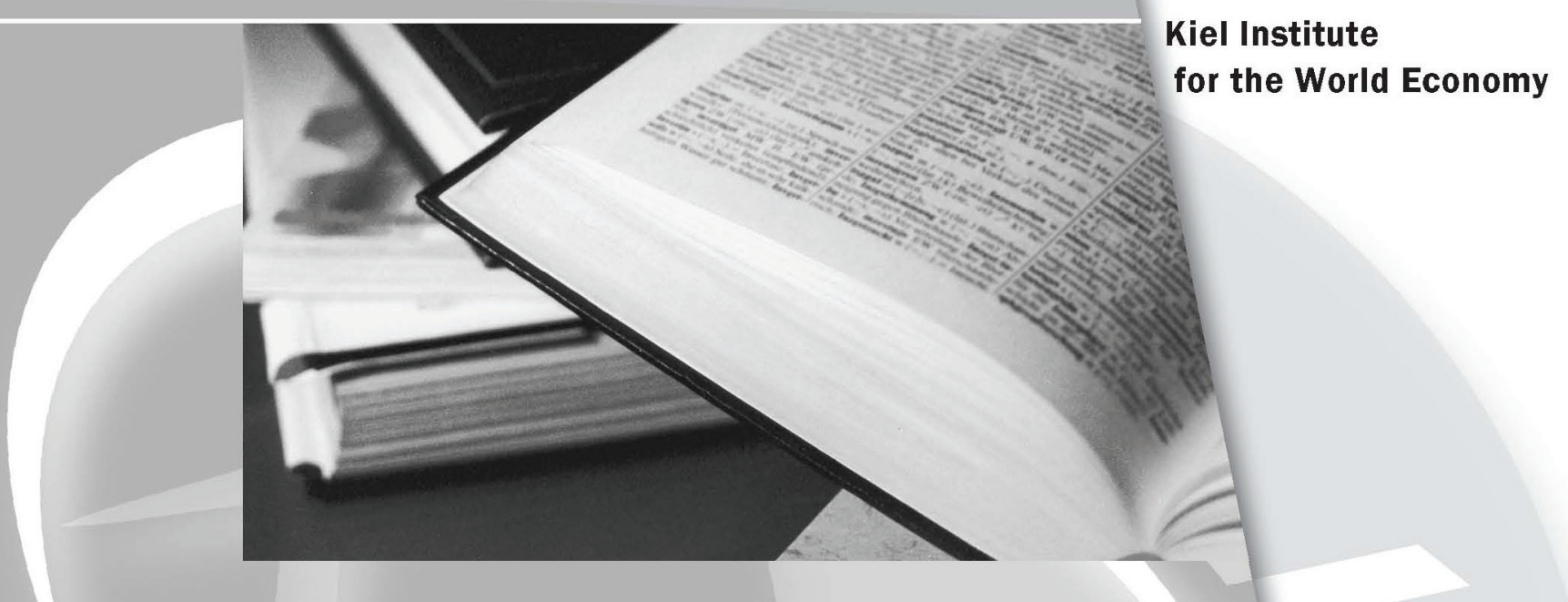

Migration and FDI: Reconciling the Standard Trade Theory with Empirical Evidence

\author{
Hubert Jayet, \\ Léa Marchal
}

No. 2039 | May 2016 
Kiel Working Paper No. 2039| May 2016

\title{
Migration and FDI: Reconciling the Standard Trade Theory with Empirical Evidence*
}

\author{
Hubert Jayet, and Léa Marchal
}

\begin{abstract}
:
This article focuses on an apparent conflict between the standard trade theory and available empirical evidence on factor flows. Theoretically, labor and capital flows must be substitutes. However, empirical papers find migration and FDI to be either substitutes or complements, depending upon the skill content of migration. To reconcile the standard theory with these empirical results, we develop a two-country general equilibrium model. We consider three factors - capital, unskilled and skilled labor - and two internationally traded goods. Countries only differ in their factor endowments. The first country is a developing country amply endowed with unskilled labor; the second one is a developed country well endowed with skilled labor. Under imperfect factor mobility, we find that capital and unskilled labor flows are substitutes, while capital and skilled labor flows are complements.
\end{abstract}

Keywords: Capital flows, Migration, Skills, Standard trade theory.

JEL classification: F11, F21, F22, J61

\author{
Hubert Jayet \\ LEM-CNRS UMR 9221, \\ University of Lille \\ Email: hubert.jayet@univ-lille1.fr
}

\author{
Léa Marchal \\ Kiel Institute for the World Economy \\ Kiellinie 66 \\ D-24105 Kiel, Germany \\ Email: lea.marchal@ifw-kiel.de
}

LEM-CNRS UMR 9221,

University of Lille

\footnotetext{
*We thank participants at the 4th annual OECD conference on Immigration in OECD countries (particularly Richard Freeman), at the 2014 Annual Meeting of the ASSET, at the 2014 ETSG, at the 5th International conference on "Economics of global interactions", at the internal seminar of the University Aldo Moro of Bari, and at the EQUIPPE internal seminar for useful comments and discussions. The usual disclaimer applies.
}

\footnotetext{
The responsibility for the contents of the working papers rests with the author, not the Institute. Since working papers are of a preliminary nature, it may be useful to contact the author of a particular working paper about results or caveats before referring to, or quoting, a paper. Any comments on working papers should be sent directly to the author.

Coverphoto: uni_com on photocase.com
} 


\section{Introduction}

This article focuses on an apparent conflict between the standard trade theory and available empirical evidence on factor flows. Theoretically, capital and labor flows must be substitutes: firms looking for workers available outside their country can attract them, generating immigration, or invest in the countries where workers are available, generating outward capital flows. ${ }^{1}$ Thus, capital and labor flows tend to move in opposite directions (Heckscher, 1919; Ohlin, 1933; Mundell, 1957; Flatters, 1972; Wong, 2006). ${ }^{2}$

This theoretical prediction is not confirmed by available empirical papers, which find that factor flows are either substitutes (they move in opposite directions) or complements (they move in the same direction), depending upon the skill content of migration. Studies carried out so far propose two main results: substitution between unskilled migration and foreign direct investment (FDI) toward migrants' origin countries (El Yaman et al., 2007; Kugler and Rapoport, 2007) and complementarity between skilled migration and FDI from migrants' origin countries (Docquier and Lodigiani, 2010; Foad, 2012; Gheasi et al., 2013; Hoxhaj et al., 2015). ${ }^{3}$

In order to reconcile the standard trade theory with these empirical results, we develop a two-country general equilibrium model resting upon the Heckscher-Ohlin framework in which differences in factor endowments between countries are sufficient to explain factor flows. The intuition behind our model is that, even if a firm invests in a developing country for benefiting from cheap unskilled labor, it needs skilled labor for managing the production process. If skilled labour is too scarce in the developing country, the firm will have to attract it from a developed country. Then, we consider three factors - capital, unskilled and skilled labor - and two transportable goods, both internationally traded. The first good is produced from labor only, skilled and unskilled workers being perfect substitutes in this sector. The production of the second good combines capital and labor, skilled and unskilled workers being perfect complements. The first industry could be akin to an exportable tertiary sector, the second one could be akin to an industrial sector where skilled workers are needed for managing the production process, hence the complementarity between the two types of labor. We assume a developing country called South, amply endowed with unskilled labor and poorly endowed with skilled labor; and a developed country called North, poorly endowed with unskilled labor and well endowed with skilled labor.

\footnotetext{
${ }^{1}$ Capital flows and labor flows are substitutes (complements) if an increase in the volume of one leads to a decrease (increase) in the volume of the other one (Wong, 2006). As an example, let us consider two countries denoted A and B; country A is capital abundant and country B is labor abundant. Assuming identical technologies across countries, returns to capital are higher in country B and wages are higher in country A. Thus, capital moves from A to B, and labor moves in the opposite direction. Then, capital and labor flows are substitutes (complements) if an exogenous increase in the capital flow from A to B generates a decrease (increase) in the labor flow from B to A. See Felbermayr et al. (2012) for a thorough discussion of the concepts.

${ }^{2}$ The literature initiated by Mundell (1957) and Flatters (1972) focuses on the degree of substitution between trade and factor mobility. It is only recently that trade theorists have focused on the link between factor flows (Wong, 2006; Felbermayr et al., 2012).

${ }^{3} \mathrm{~A}$ number of studies also find a link of complementarity between skilled migration and FDI toward migrants' origin countries which is mainly due to network effects (El Yaman et al., 2007; Kugler and Rapoport, 2007; Javorcik et al., 2011). This literature is presented in Section 2.
} 
Assuming that factors are imperfectly mobile between countries - firms ask for a risk premium for moving capital to the South and migrant workers must cover a migration cost - we find that capital flows and unskilled labor flows are substitutes, and that capital flows and skilled labor flows are complements.

Let us illustrate our results with a reduction in political barriers between the two countries that are at equilibrium (both being abundant in capital). When the risk premium decreases, returns to capital increase in the South, so that some firms relocate to the South. Unskilled workers are now more demanded in the Southern industrial sector, which generates the return of Southern migrants from the North. Skilled workers are also more demanded because these firms need qualified workers to implement their technology and to manage their foreign workforce. This generates the migration of Northern skilled workers to the South. ${ }^{4}$ To sum up, when North-South capital flows increase, then South-North unskilled migration decreases and North-South skilled migration increases.

This article contributes to the literature by reconciling the standard trade theory with available empirical evidence on the FDI-migration nexus. So far, almost no attempt has been made to show how standard economic forces that are behind international trade may lead to complementarity of capital and labor flows. The usual explanations for this empirical result come from outside the standard trade theory, focusing on the impact of migrant networks on investment costs and on agglomeration effects. We show that even without networks and agglomeration effects, we can explain the empirical evidence. Besides, our general equilibrium model allows us to analyze both directions of the FDI-migration nexus, and to evidence both substitution and complementarity in a single North-South framework.

The article is structured as follows. In Section 2, we examine the literature and the contribution of our paper. In Section 3, we introduce the two-country model. In Section 4, we introduce factor mobility in the model and analyze the effects of factor transfers the relationship between factor flows. We conclude in Section 5.

\section{Substitution and complementarity between factor flows}

\subsection{Empirical evidence on the FDI-migration nexus}

A small number of empirical studies finds that FDI and migration are substitutes, which is in line with the theoretical predictions of the standard trade theory. Aroca and Maloney (2005) evaluate the mechanisms through which FDI and trade from the United States (US) to Mexico impact migration in the reverse direction. They show that a greater exposure to FDI and trade deters migration, the effects being partly at play through the labor market. In a management

\footnotetext{
${ }^{4}$ Laczko and Brian (2013) emphasize that North-South migration consists mainly of return migrants, young professionals in search of new opportunities and skilled expatriates sent by multinational firms to manage their subsidiaries. In particular, multinational enterprises use skilled worker transfers to control and co-ordinate their headquarter operations with their subsidiary operations and to ensure tacit knowledge transfers (Kogut and Zander, 2003; Williams, 2007).
} 
study, Sauvant et al. (1993) argue that FDI decrease migration incentives in the short run - by providing would-be migrants with employment opportunities - and in longer term - by enhancing growth and reducing poverty. This argument has also been proposed in a sociological study by Sassen (1988).

Other papers find factor flows to be complements. Using data on 25 less-developed countries (LDCs) over the 1985-2000 period, Sanderson and Kentor (2008) show that FDI stocks positively impact emigration in the long run. Then, D'Agosto et al. (2013) study FDI flows from OECD to developing countries and migration in the reverse direction over the 1991-2001 period. They show that FDI inflows positively impact the human capital accumulation of the developing country, which increase wages, which in turn can decrease emigration. On the other hand, they find that FDI inflows can increase emigration by relaxing the budget constraint of would-be migrants.

Analyzing the reverse causality, a number of studies shows that migrants spread information between their origin and host countries, which strengthens bilateral economic relations. Studying European states over the 1995-2007 period, De Simone and Manchin (2012) find that migration from eastern to western countries positively impacts FDI in the reverse direction. Ricketts (1987); Gao (2003); Tong (2005); Bhattacharya and Groznik (2008) find similar results. Finally, Buch et al. (2006) analyze agglomeration effects with state-level German data over the 1991-2002 period. They find that stocks of inward FDI and of immigrants have similar determinants, and that higher stocks of inward FDI are associated to larger foreign population from the same origin country.

No straightforward consensus can be derived from this literature, probably because it does not consider the skill content of migration. In the following part, we review available studies making the difference between skilled and unskilled migration.

\subsection{Introducing skills in the study of the FDI-migration nexus}

Most of this literature analyses how migration impacts FDI. In their study of European countries over the 1990-2000 period, El Yaman et al. (2007) find that unskilled migrants negatively impact outward FDI toward their origin countries, while skilled migrants positively impact outward FDI. Kugler and Rapoport (2007) corroborate these results. Analyzing US data over the same period, they find contemporaneous substitution between low skilled migration and outward FDI, and dynamic complementarity between high skilled migration and outward FDI. Javorcik et al. (2011) further explore the complementarity between skilled migration and outward FDI. They show that immigrants provide native firms with better information on their origin countries. Analyzing US immigration and US FDI into 56 migrants' origin countries in 1990 and 2000, they find that immigration, and particularly skilled immigration, positively impacts outward FDI.

Skilled immigration may also impact inward FDI. Foad (2012) analyses FDI and immigration from 10 source countries to the 50 US states between 1991 and 2004. He finds that immigrant communities in the US attract FDI from their origin countries, this effect being stronger for individuals with a high education level. Using a sample of 114 countries over the 1990-2000 period, Docquier and Lodigiani (2010) also find that inward FDI is positively related to skilled 
immigration. Finally, Gheasi et al. (2013) study the impact of migration on both inward and outward FDI, and evidence a relation of complementarity which is stronger for skilled immigrants.

Only few papers investigate in what extent FDI impacts unskilled and skilled migration. Hoxhaj et al. (2015) analyze the determinants of the employment of foreign skilled workers by foreign firms operating in Sub-Saharan African countries. Using firm-level data for 2008, they find a link of complementarity between foreign capital inflows and the employment of foreign skilled workers by foreign firms. Finally, using data over the 1990-2000 period, Wang et al. (2013) show that FDI from OECD countries toward LDCs tends to reduce migration of individuals with tertiary and secondary education in the reverse direction, this result being at odds with most of the literature.

Overall, FDI and unskilled migration between developed and developing countries seem to be substitutes: the increase in one factor flow decreases the volume of the other factor flow and flows are moving in opposite directions. FDI and skilled migration seem to be complements: the increase in one factor flow increases the volume of the other factor flow. A number of papers finds complementarity when FDI and skilled workers move in opposite directions, while other papers find this result when factors are moving in the same direction. The review of these empirical studies is summarized in Table 1 .

\subsection{Theoretical background and contribution of the paper}

The theoretical explanations for these results come from outside the literature on international trade. The usual one focuses on the effect of migrant networks on trade and investment costs. In their paper, De Simone and Manchin (2012) extend the 2x2x2 model of fragmentation and multinational production of Venables (1999) and show that, when immigrants relax the informational constraint faced by firms, foreign investment increases. Then, Federici and Giannetti (2010) develop a continuous time dynamic model. They consider a small open developing economy which lacks capital and skilled labor. They assume that migration is temporary, and that the capital stock in the developing country is generated by capital inflows from developed countries hosting migrants. They show that return migration increases the human capital stock of the country and acts as an information revealing network which attracts FDI.

Some other mechanisms can be used to generate substitution or complementarity between factor flows. For instance, Wong (2006) introduces Marshallian externalities in a standard twocountry Heckscher-Ohlin framework, and finds that capital and labor movements are most likely substitutes. Then, Anwar (2008) develops a small open economy characterized by unrestricted international capital mobility and where the supply of public infrastructures is endogenous. The author shows that an increase in labor supply may either increase or decrease foreign investment, depending on the provision of public infrastructures.

So far, almost no attempt has been made to show how simple economic forces behind the standard trade theory may lead to complementarity between labor and capital flows. Our article intends to fill this gap by proposing a theoretical model resting upon the Heckscher-Ohlin 


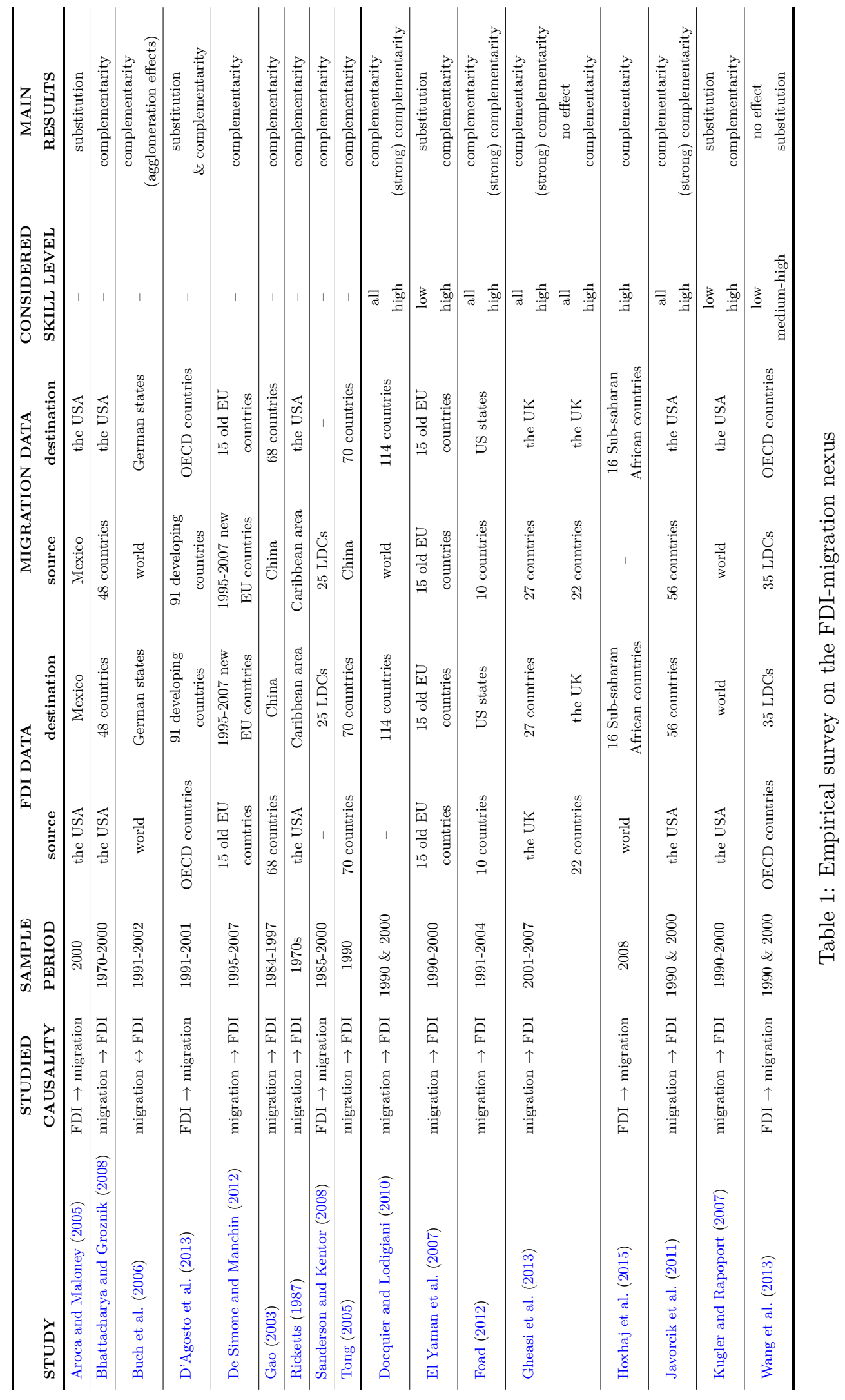


framework. In such a two-country model, asymmetric factor scarcities allow for corner solutions that are sufficient to generate both substitution and complementarity between factor flows. Our model allows us to illustrate how migration may impact capital flows (as most of the theoretical literature does), but also to understand the reverse causality.

Our work shows that, in addition to network effects, standard industrial mechanisms can also generate complementarity and substitution. We corroborate empirical studies showing that unskilled migration and FDI toward migrant's origin countries are negatively related (El Yaman et al., 2007; Kugler and Rapoport, 2007) and that skilled migration and FDI from migrant's origin countries are positively related (Docquier and Lodigiani, 2010; Foad, 2012; Gheasi et al., 2013; Hoxhaj et al., 2015).

However, our model does not explain empirical findings suggesting that skilled migration and FDI toward migrant's origin countries are complements (El Yaman et al., 2007; Kugler and Rapoport, 2007; Javorcik et al., 2011). Due to the production structure of the capitalist sector that requires all three factors, in a country under skilled labor and capital deprivation (as a developing country), it is not possible to observe emigration of skilled workers together with an arrival of foreign firms. Such an empirical result may better be explained by network effects.

Then, our work can be related to Ricardian models in which factor flows are motivated by the technological superiority of the destination country. Among others, Davis and Weinstein (2002) develop a Ricardian model with a composite production factor. They show that skilled labor, unskilled labor and capital have a simultaneous incentive to enter the country with the highest technology; factor flows are thus complements. However, only complementarity arises in this type of framework.

Last, Felbermayr et al. (2012) review both empirical and theoretical research on the relations between trade, capital flows and migration. Their work underlines the different mechanisms (Heckscher-Ohlin type, Ricardian type and others) that can generate substitution and complementarity between factor flows.

\section{The model}

\subsection{The one-country model}

Let us start considering a single country, called South. The country combines three inputs, capital, skilled and unskilled labor, for producing two transportable goods, both internationally traded. The first good is the output of a non-capitalist sector. Skilled and unskilled labor are perfect substitutes and produce under constant returns to scale. The production task to be carried out is basic, consequently both types of workers have the capacity to perform it although skilled workers are more efficient in doing so. The production function of this sector is: $Q_{1}=A\left(U_{1}+c S_{1}\right), Q_{1}$ being the output, $U_{1}$ and $S_{1}$ the respective inputs of unskilled and skilled labor, $c$ a constant greater than unity, and $A$ a positive constant. The intensive form of this production function is given by equation (1), where $u_{1}$ and $s_{1}$ are technical coefficients i.e. the respective quantities 
of unskilled and skilled labor needed to produce one unit of output, respectively $u_{1}=\frac{U_{1}}{Q_{1}}$ and $s_{1}=\frac{S_{1}}{Q_{1}}$.

$$
1=A\left(u_{1}+c s_{1}\right)
$$

The second sector is a capitalist or industrial sector, as it employs capital in addition to labor. It is characterized by the following Cobb-Douglas function: $Q_{2}=B K^{\beta}\left[\min \left(U_{2}, S_{2}\right)\right]^{1-\beta}, Q_{2}$ being the output, $K, U_{2}$ and $S_{2}$ the respective inputs of capital, unskilled labor and skilled labor employed in the sector, $\beta$ a constant between zero and unity, and $B$ a positive constant. Then in the industrial sector, returns to scale are constant, capital and labor are imperfect substitutes to each other, and skilled and unskilled labor are perfect complements. This functional form is the simplest solution for taking account of the fact that, when a firm makes FDI for benefiting from cheap unskilled labor, it also needs some skilled labor for managing the plant. Production involves two complementary tasks, a simple one and a complex one. The complex task can be carried out by skilled workers only. Both types of workers can carry out the simple tasks but, usually, wages being higher for the complex task, only unskilled workers will accept the simple one. The intensive form of the production function is given by equation (2), where $k$ and $l$ are technical coefficients, respectively $k=\frac{K}{Q_{2}}$ and $l=\min \left(u_{2}, s_{2}\right)$, with $u_{2}=\frac{U_{2}}{Q_{2}}$ and $s_{2}=\frac{S_{2}}{Q_{2}}$.

$$
1=B k^{\beta} l^{1-\beta}
$$

Both outputs are perfectly mobile internationally, thus their prices are set up in international markets. We choose the non-capitalist good as the numeraire. Its price equals unity, the price of the industrial good being denoted $p$. We start examining what happens when all the three factors are mobile between sectors of the economy but internationally immobile, so that their prices are determined locally. In perfectly competitive markets, the marginal productivity of each factor equalizes its price. In the non-capitalist sector, as long as both types of labor are employed, wages are given by equations (3) and (4), where $w_{u}$ denotes the wage of unskilled labor and $w_{s}$ denotes the wage of skilled labor.

$$
\begin{aligned}
& w_{u}=A \\
& \frac{w_{s}}{c}=A
\end{aligned}
$$

In the capitalist sector, factor prices are given by equations (5) and (6), where $\rho$ denotes the returns to capital.

$$
\begin{aligned}
\rho k & =\beta p \\
\left(w_{u}+w_{s}\right) l & =(1-\beta) p
\end{aligned}
$$

Equilibrium implies the full employment of inputs. The total endowment of each factor equalizes the global demand by the two sectors of the economy:

$$
\begin{aligned}
U & =u_{1} Q_{1}+l Q_{2} \\
S & =s_{1} Q_{1}+l Q_{2} \\
K & =k Q_{2}
\end{aligned}
$$


The solution to this system is developed in appendix, Section A.1. For both types of labor to be employed in the non-capitalist sector, the following inequality must hold:

$$
K(B l)^{1 / \beta}=K\left[\frac{(1-\beta) B p}{(1+c) A}\right]^{1 / \beta}<\min (U, S)
$$

What happens when this inequality does not hold depends upon the respective sizes of the skilled and unskilled labor forces. If there are less skilled workers than unskilled workers $(S<U)$, there will be no skilled worker in the non-capitalist sector, so that the skilled wage will no longer be given by equation (4). If there are more skilled workers than unskilled workers $(S>U)$, there will be no unskilled worker in the non-capitalist sector, so that the unskilled wage will no longer be given by equation (3). Both corner solutions are developed in appendix, Section A.2.

\subsection{The North-South model}

Let us add a second country, called North. Apart from their factor endowments, both countries are similar to each other. Every variable $x$ for the South will correspond to the variable $x^{*}$ for the North. The world factor endowments are given by the sum of North and South endowments, such that $\bar{U}=U+U^{*}, \bar{S}=S+S^{*}$ and $\bar{K}=K+K^{*}$. The South is a developing economy, amply endowed with unskilled labor and poorly endowed with skilled labor. Conversely, the North is a developed country, poorly endowed with unskilled labor and well endowed with skilled labor.

In this two-country economy, goods are perfectly mobile without any transaction cost. Thus, there is a world market for each good and the local price equals the world price in both countries. As in the previous section, we normalize the price of the non-capitalist good to unity and denote $p$ the price of the industrial good.

In both countries, workers have preferences represented by a Cobb-Douglas utility function given by: $v\left(q_{1}, q_{2}\right)=q_{1}^{\gamma} q_{2}^{1-\gamma}$, where $q_{1}$ denotes the worker's consumption of the non-capitalist good, $q_{2}$ denotes her consumption of the capitalist good, and $\gamma$ is a constant between zero and unity. This utility function implies that every consumer devotes a share $\gamma$ of her income to buy the non-capitalist good and a share $(1-\gamma)$ to buy the capitalist good. Aggregating over all consumers and equalizing the world supply and the world demand, we get:

$$
\begin{aligned}
Q_{1}+Q_{1}^{*} & =\gamma \bar{I} \\
p\left(Q_{2}+Q_{2}^{*}\right) & =(1-\gamma) \bar{I}
\end{aligned}
$$

where $\bar{I}=I+I^{*}=Q_{1}+Q_{1}^{*}+p\left(Q_{2}+Q_{2}^{*}\right)$ denotes the world income, $I=w_{u} U+w_{s} S+\rho K$ is the income generated in the South, and $I^{*}=w_{u}^{*} U^{*}+w_{s}^{*} S^{*}+\rho^{*} K^{*}$ is the income generated in the North. The Walras equality implies that we only need to check one of these conditions. The conditions (11) and (12) are equivalent to:

$$
(1-\gamma)\left(Q_{1}+Q_{1}^{*}\right)=\gamma p\left(Q_{2}+Q_{2}^{*}\right)
$$

It implies that, at equilibrium, the part of the income generated by the non-capitalist sector devoted to buy the capitalist good must equal the part of the income generated by the capitalist sector devoted to buy the non-capitalist good. 
As for factors of production (capital, skilled and unskilled labor), they are imperfectly mobile between countries. Initially, the global capital stock, $\bar{K}$, is fully owned by the North, but some part of this stock may be invested in the South. For accepting to invest in the South, capitalists must get higher returns than in the North, which may be interpreted as an exogenous risk premium, $\tau(>0)$. Then, we can write:

$$
K>0 \Rightarrow \rho=\tau+\rho^{*}
$$

Workers are internationally mobile. The initial populations of skilled and unskilled labor in the South and in the North are given by $S_{0}, U_{0}, S_{0}^{*}$ and $U_{0}^{*}$. After migration, populations are given by $S, U, S^{*}$ and $U^{*}$. Since the North is well endowed with skilled labor but not with unskilled labor, and the South is well endowed with unskilled labor but not with skilled labor, we are interested in movements of skilled workers from the North to the South, and of unskilled workers from the South to the North. As there are migration costs, for skilled workers to accept migrating from the North to the South, they must get a higher wage in the South, the difference needed for covering migration costs being $\mu_{s}(>0)$. Then, we can write

$$
S>S_{0} \Rightarrow w_{s}=\mu_{s}+w_{s}^{*}
$$

Similarly, for unskilled workers to accept migrating from the South to the North, they must get a higher wage in the North, the difference needed for covering migration costs being $\mu_{u}(>0)$. Then, we can write:

$$
U^{*}>U_{0}^{*} \Rightarrow w_{u}^{*}=\mu_{u}+w_{u}
$$

\section{Factors mobility}

\subsection{Initial situation: No factor mobility}

Let us first look at what happens when all the factors are immobile. The whole stock of capital is invested in the North $\left(K^{*}=\bar{K}\right)$, so that the South has no capital $(K=0)$. In both countries, the skilled and unskilled labor force equal the initial endowments: $S=S_{0}, U=U_{0}, S^{*}=S_{0}^{*}$, $U^{*}=U_{0}^{*}$.

In the South, the capitalist sector is inactive and all the workers are hired by the non-capitalist sector. In each sector, production equals:

$$
\begin{aligned}
& Q_{1}=A(U+c S) \\
& Q_{2}=0
\end{aligned}
$$

The wages of both types of workers are determined by the non-capitalist sector only. Unskilled workers are paid: $w_{u}=A$ and skilled workers are paid: $w_{s}=c A$. Then, the global income earned by workers in the South equals:

$$
I=A(U+c S)
$$


In the North, the capital endowment is large enough and the unskilled workforce is small enough for all unskilled workers to be employed by the capitalist sector, the non-capitalist sector employing skilled workers only. Then, the following inequality is met:

$$
U^{*}<\left[\frac{(1-\beta) B p}{(1+c) A}\right]^{1 / \beta} \bar{K}<S^{*}
$$

In each sector, outputs are given by:

$$
\begin{aligned}
& Q_{1}^{*}=A c\left(S^{*}-U^{*}\right) \\
& Q_{2}^{*}=B(\bar{K})^{\beta}\left(U^{*}\right)^{1-\beta}
\end{aligned}
$$

Unskilled workers are paid: $w_{u}^{*}=(1-\beta) B p\left(\frac{\bar{K}}{U^{*}}\right)^{\beta}-c A$, skilled workers are paid: $w_{s}^{*}=c A$ and returns to capital are given by: $\rho^{*}=\beta B p\left(\frac{U^{*}}{\bar{K}}\right)^{1-\beta} \cdot{ }^{5}$ Then, the global income earned in the North equals:

$$
I^{*}=c A\left(S^{*}-U^{*}\right)+p B(\bar{K})^{\beta}\left(U^{*}\right)^{1-\beta}
$$

The world income is given by:

$$
\bar{I}=A\left[U+c\left(\bar{S}-U^{*}\right)\right]+p B(\bar{K})^{\beta}\left(U^{*}\right)^{1-\beta}
$$

and the equilibrium condition (13) gives the world price of the capitalist good:

$$
p=\frac{1-\gamma}{\gamma} \frac{Q_{1}+Q_{1}^{*}}{Q_{2}+Q_{2}^{*}}=\frac{(1-\gamma)}{\gamma} \frac{A\left[U+c\left(\bar{S}-U^{*}\right)\right]}{B\left[(\bar{K})^{\beta}\left(U^{*}\right)^{1-\beta}\right]}
$$

so that the condition (17) becomes:

$$
\frac{S^{*}}{U^{*}}>\theta^{\frac{1}{\beta}}>1
$$

where:

$$
\theta^{\frac{1}{\beta}}=\left[\frac{(1+c)}{(1-\beta)} \frac{\gamma}{(1-\gamma)} \frac{U^{*}}{U+c \bar{S}-c U^{*}}\left(\frac{S^{*}}{U^{*}}\right)^{\beta}\right]^{\frac{1}{\beta}}
$$

At this stage, both capital and unskilled labor have an incentive to move. In the North, returns to capital are given by: $\rho^{*}=\beta B p\left(\frac{U^{*}}{\bar{K}}\right)^{1-\beta}$. If a small quantity of capital were invested in the South, returns to capital would be: $\rho=\beta p k^{-1}=\beta B p\left[\frac{(1-\beta) B p}{(1+c) A}\right]^{\frac{1}{\beta}-1}$. As long as the inequality $U^{*}<\left[\frac{(1-\beta) B p}{(1+c) A}\right]^{\frac{1}{\beta}} K<S^{*}$ holds, returns to capital are higher in the South than in the North $\left(\rho>\rho^{*}\right)$.

Therefore, if there were no risk premium, capital would have an incentive to move from the North to the South. With a positive risk premium, capital has an incentive to relocate to the

\footnotetext{
${ }^{5}$ As noted above, for simplifying matters, we are only looking at the case where $w_{u}^{*}<w_{s}^{*}$, so that skilled workers do not take unskilled jobs. This situation implies that unskilled workers are not too scarce in the North. More precisely, after a straightforward calculation, we find that the following inequality must hold: $\frac{c U^{*}}{U+c \bar{S}}>\frac{(1-\beta)(1-\gamma)}{1+\gamma-\beta+\beta \gamma}$.
} 
South as long as: $\rho-\rho^{*}>\tau$, which implies that:

$$
p^{\frac{1}{\beta}}\left[\frac{(1-\beta) B}{(1+c) A}\right]^{\frac{1}{\beta}-1}-p\left(\frac{U_{0}^{*}}{\bar{K}}\right)^{1-\beta}>\frac{\tau}{\beta B}
$$

Introducing the expression of the price in this equation, we obtain the following condition:

$$
\frac{\gamma \bar{K}}{\beta(1-\gamma) A} \tau<\left[\frac{(1-\beta)(1-\gamma)}{(1+c) \gamma}\right]^{\frac{1}{\beta}-1}\left[\frac{U_{0}+c\left(\bar{S}-U_{0}^{*}\right)}{U_{0}^{1-\beta}}\right]^{\frac{1}{\beta}}-\left[U_{0}+c\left(\bar{S}-U_{0}^{*}\right)\right]
$$

Note that having the whole capital stock invested in the North is not an equilibrium.

The wage of unskilled workers in the North is higher than the wage in the South: $(1-\beta) B p\left(\frac{K^{*}}{U^{*}}\right)^{\beta}-$ $c A>A$. Thus, if they were allowed to migrate at no cost, unskilled workers would move from the South to the North. When there are positive migration costs, Southern unskilled workers have an incentive to head North as long as: $w_{u}^{*}-w_{u}>\mu_{u}$, which implies that:

$$
(1-\beta) B p\left(\frac{\bar{K}}{U_{0}^{*}}\right)^{\beta}-(1+c) A>\mu_{u}
$$

Introducing the expression of the price in this last equation, we obtain the following condition:

$$
\frac{\gamma}{A} \mu_{u}<(1-\beta)(1-\gamma)\left(\frac{U_{0}+c \bar{S}}{U_{0}^{*}}-c\right)+(c-1) \gamma
$$

Note that having no migration of unskilled workers from the South to the North is not an equilibrium.

In the sequel, we assume that both conditions (18) and (19) hold, so that having all the capital invested in the North and no unskilled migration from the South to the North is not an equilibrium. Therefore, we only look at equilibria with capital invested in the North and unskilled Southern workers employed in the North.

\subsection{Types of equilibria}

Let us look at what happens, at equilibrium, when both countries host a part of the capital stock and when a number of unskilled migrants originating from the South work in the North. We can identify two equilibria of this type, depending upon the constraints faced by the industrial sector in both countries.

The first case occurs when the equilibrium stocks of capital invested in both countries are large. In each country, the capitalist sector is large enough to drain all the scarce labor - skilled labor in the South and unskilled labor in the North - from the non-capitalist sector, which only employs the abundant labor. In this case, the following inequalities hold:

$$
\begin{gathered}
K>\left[\frac{(1+c) A}{(1-\beta) B p}\right]^{\frac{1}{\beta}} \min (U, S)=\left[\frac{(1+c) A}{(1-\beta) B p}\right]^{\frac{1}{\beta}} S \\
\bar{K}-K>\left[\frac{(1+c) A}{(1-\beta) B p}\right]^{\frac{1}{\beta}} \min \left(U^{*}, S^{*}\right)=\left[\frac{(1+c) A}{(1-\beta) B p}\right]^{\frac{1}{\beta}} U^{*}
\end{gathered}
$$


so that:

$$
\left[\frac{(1+c) A}{(1-\beta) B p}\right]^{\frac{1}{\beta}} S<K<\bar{K}-\left[\frac{(1+c) A}{(1-\beta) B p}\right]^{\frac{1}{\beta}} U^{*}
$$

or equivalently:

$$
\min \left[\frac{Q_{2}}{B K}, \frac{Q_{2}^{*}}{B(\bar{K}-K)}\right]<\left[\frac{(1-\beta) B p}{(1+c) A}\right]^{\frac{1}{\beta}-1}
$$

Note that this equilibrium requires a large enough global capital stock. If the global capital stock is too small, the capitalist sector in each country cannot be large enough to employ all the scarce labor, so that this labor is still employed by the non-capitalist sector. This situation cannot be an equilibrium, as it implies that both skilled and unskilled workers earn the same wages in both countries (the wages equal to their marginal productivities in the non-capitalist sector). Then, returns to capital are the same in both countries and the equilibrium condition (14) is not met.

The second case occurs when the equilibrium stock of capital invested in the South and the equilibrium population of unskilled migrants in the North are small. Then, the basic structure

of the economy does not change with respect to the initial situation: the capitalist sector in the South is not able to employ all the skilled workers, so that some of them are still working in the non-capitalist sector; and the capitalist sector in the North is large enough for employing all the unskilled workers, so that the non-capitalist sector employs skilled workers only. Then, the following constraints are met:

$$
\begin{aligned}
K< & {\left[\frac{(1+c) A}{(1-\beta) B p}\right]^{\frac{1}{\beta}} \min (U, S)=\left[\frac{(1+c) A}{(1-\beta) B p}\right]^{\frac{1}{\beta}} S } \\
{\left[\frac{(1+c) A}{(1-\beta) B p}\right]^{\frac{1}{\beta}} \min \left(U^{*}, S^{*}\right) } & =\left[\frac{(1+c) A}{(1-\beta) B p}\right]^{\frac{1}{\beta}} U^{*}<\bar{K}-K
\end{aligned}
$$

so that:

$$
K<\min \left\{\left[\frac{(1+c) A}{(1-\beta) B p}\right]^{\frac{1}{\beta}} S, \bar{K}-\left[\frac{(1+c) A}{(1-\beta) B p}\right]^{\frac{1}{\beta}} U^{*}\right\}
$$

or equivalently:

$$
\left(\frac{U^{*}}{\bar{K}-K}\right)^{1-\beta}<\left[\frac{(1-\beta) B p}{(1+c) A}\right]^{\frac{1}{\beta}-1}<\left(\frac{S}{K}\right)^{1-\beta}
$$

\subsection{Large investment to the South}

\subsubsection{The equilibrium}

Let us look at the first case, when the equilibrium capital stocks invested in both countries are large. This equilibrium is the most likely to prevail in the real world. Capital appears to be worldly abundant. It has long been localized in northern industrial countries but, particularly since the late 1990's, we observe a significant increase in FDI toward emerging and developing countries.

In each country, the capitalist sector is large enough to drain all the scarce labor - skilled labor in the South and unskilled labor in the North - from the non-capitalist sector which only employs the abundant labor. 
In the South, sectoral outputs are given by:

$$
\begin{aligned}
& Q_{1}=A(U-S) \\
& Q_{2}=B K^{\beta} S^{1-\beta}
\end{aligned}
$$

Skilled workers are employed by the industrial sector only. Skilled workers are paid: $w_{s}=$ $(1-\beta) B p\left(\frac{K}{S}\right)^{\beta}-A$, unskilled workers are paid: $w_{u}=A$ and returns to capital are given by: $\rho=\beta B p\left(\frac{S}{K}\right)^{1-\beta}$. The income generated in the South equals:

$$
I=A(U-S)+p B K^{\beta} S^{1-\beta}
$$

In the North, sectoral outputs are given by:

$$
\begin{aligned}
& Q_{1}^{*}=A c\left(S^{*}-U^{*}\right) \\
& Q_{2}^{*}=B(\bar{K}-K)^{\beta}\left(U^{*}\right)^{1-\beta}
\end{aligned}
$$

Skilled workers are paid: $w_{s}^{*}=c A$, unskilled workers are paid: $w_{u}^{*}=(1-\beta) B p\left(\frac{\bar{K}-K}{U^{*}}\right)^{\beta}-c A$, and returns to capital are given by: $\rho^{*}=\beta B p\left(\frac{U^{*}}{\bar{K}-K}\right)^{1-\beta}$. The income generated in the North equals:

$$
I^{*}=c A\left(S^{*}-U^{*}\right)+p B(\bar{K}-K)^{\beta}\left(U^{*}\right)^{1-\beta}
$$

The world income equals:

$$
\bar{I}=A(U-S)+p B K^{\beta} S^{1-\beta}+c A\left(S^{*}-U^{*}\right)+p B(\bar{K}-K)^{\beta}\left(U^{*}\right)^{1-\beta}
$$

The equilibrium condition (13) has an explicit solution, the world price of the industrial good being:

$$
p=\frac{1-\gamma}{\gamma} \frac{Q_{1}+Q_{1}^{*}}{Q_{2}+Q_{2}^{*}}=\frac{1-\gamma}{\gamma} \frac{A\left(U-S+c S^{*}-c U^{*}\right)}{B\left[K^{\beta} S^{1-\beta}+(\bar{K}-K)^{\beta}\left(U^{*}\right)^{1-\beta}\right]}
$$

Introducing the expression of the price in the condition (20), we find a condition on the capital endowments in each country:

$$
\left[\phi\left(\frac{\widehat{Q}}{U^{*}}-1\right)\left(\frac{U^{*}}{S}\right)^{1-\beta}\right]^{-1 / \beta}<\frac{\bar{K}}{K}-1<\left[\phi\left(\frac{\widehat{Q}}{S}-1\right)\left(\frac{S}{U^{*}}\right)^{1-\beta}\right]^{1 / \beta}
$$

where $\phi=\frac{(1-\beta)(1-\gamma)}{(1+c) \gamma}$ and $\widehat{Q}=U-S+c\left(S^{*}-U^{*}\right)$.

At international equilibrium, the conditions (14), (15) and (16) are met. These three conditions may be written as:

$$
\begin{aligned}
& \tau=\rho-\rho^{*}=\beta B p\left[\left(\frac{S}{K}\right)^{1-\beta}-\left(\frac{U^{*}}{\bar{K}-K}\right)^{1-\beta}\right] \\
& \mu_{s}=w_{s}-w_{s}^{*}=(1-\beta) B p\left(\frac{K}{S}\right)^{\beta}-(1+c) A \\
& \mu_{u}=w_{u}^{*}-w_{u}=(1-\beta) B p\left(\frac{\bar{K}-K}{U^{*}}\right)^{\beta}-(1+c) A
\end{aligned}
$$

where the price, $p$, is given by equation (22). 


\subsubsection{Marginal change in the risk premium or in the migration costs}

At equilibrium, we analyze what happens to the factor allocation between countries when either $\tau, \mu_{u}$ or $\mu_{s}$ increases at the margin. Calculations are presented in appendix, Section A.3 and lead to the results presented in Table 2 .

\begin{tabular}{c|cc} 
& $\frac{d \tau}{\tau}$ & $\frac{d \mu_{u}}{\mu_{u}+(1+c) A}$ \\
\hline$\frac{d K}{K}$ & - & + \\
$\frac{d S}{S}$ & - & + \\
$\frac{d U^{*}}{U^{*}}$ & + & -
\end{tabular}

Table 2: Changes induced by a marginal increase in $\tau$ or $\mu_{u}$ (large investment case)

At equilibrium, a marginal increase in the risk premium implies that capitalists expect higher returns in the North than in the South, such that: $\tau>\rho-\rho^{*}$. In this case, more capital remains in the North to the detriment of the South $\left(\frac{d K}{K}<0\right)$. At equilibrium, the industrial sector faces a shortage of unskilled labor in the North and a shortage of skilled labor in the South. Thus, when the capitalist sector gets larger in the North and smaller in the South, the demand for unskilled labor increases in the North while the demand for skilled labor decreases in the South. Consequently, both unskilled and skilled labor stocks increase in the North to the detriment of the South $\left(\frac{d U^{*}}{U^{*}}>0\right.$ and $\left.\frac{d S}{S}<0\right)$.

A marginal increase in the migration cost for unskilled workers implies that Southern unskilled workers have less incentives to go North, such that: $\mu_{u}>w_{u}^{*}-w_{u}$. In this case, the stock of unskilled labor increases in the South to the detriment of the North $\left(\frac{d U^{*}}{U^{*}}<0\right)$. Thus, in the North, the capitalist sector gets smaller when the stock of unskilled labor decreases and its demand for capital drops. In the South, the industrial sector gets larger, but it is compelled by skilled labor; thus, its demand for skilled labor increases. Consequently, both capital and skilled labor stocks increase in the South to the detriment of the North $\left(\frac{d S}{S}>0\right.$ and $\left.\frac{d K}{K}>0\right)$.

A marginal increase in the migration cost for skilled workers implies that the cost to head South becomes higher, such that: $\mu_{s}>w_{s}-w_{s}^{*}$. Although the signs of $\frac{d K}{K}, \frac{d S}{S}$ and $\frac{d U^{*}}{U^{*}}$ are undetermined, we expect the following results: The stock of skilled labor should decrease in the South to the benefit of the North. In the South, the industrial sector is compelled by skilled labor, so the sector should get smaller when the stock of skilled labor decreases, and its demand for capital should drop. In the North, the industrial sector is compelled by unskilled labor, so the demand for unskilled labor should increase. As a result, we expect both capital and unskilled labor stocks to increase in the North to the detriment of the South.

Thus, changes in the risk premium and in the migration cost of unskilled workers both lead to capital flows and unskilled migration moving in opposite directions, and to capital flows and skilled migration moving in the same direction. For instance, a decrease in the risk premium leads to an increase in North-South capital flows. This, in turn, leads to an increase in North-South skilled migration and to a decrease in South-North unskilled migration. Then, we can conclude that FDI and unskilled migration are substitutes, while FDI and skilled migration are complements. 


\subsection{Small investment to the South}

\subsubsection{The equilibrium}

Let us analyze the second case, when the equilibrium stock of capital invested in the South and the equilibrium population of unskilled migrants are small enough, so that the condition (21) is met.

In the South, sectoral outputs are given by:

$$
\begin{aligned}
& Q_{1}=A\left\{U+c S-(1+c) K\left[\frac{B(1-\beta) p}{(1+c) A}\right]^{\frac{1}{\beta}}\right\} \\
& Q_{2}=K B^{\frac{1}{\beta}}\left[\frac{(1-\beta) p}{(1+c) A}\right]^{\frac{1}{\beta}-1}
\end{aligned}
$$

Because the non-capitalist sector still employs both skilled and unskilled workers, wages are determined by the non-capitalist sector only, so that $w_{u}=A$ and $w_{s}=c A$. Returns to capital are given by: $\rho=\beta(B p)^{\frac{1}{\beta}}\left[\frac{1-\beta}{(1+c) A}\right]^{\frac{1}{\beta}-1}$. Then, the global income generated in the South equals:

$$
I=(U+c S) A+\beta(B p)^{\frac{1}{\beta}}\left[\frac{1-\beta}{(1+c) A}\right]^{\frac{1}{\beta}-1} K
$$

In the North, sectoral outputs are given by:

$$
\begin{aligned}
& Q_{1}^{*}=A c\left(S^{*}-U^{*}\right) \\
& Q_{2}^{*}=B(\bar{K}-K)^{\beta}\left(U^{*}\right)^{1-\beta}
\end{aligned}
$$

Note that, using the expressions of $Q_{2}$ and $Q_{2}^{*}$, the small investment condition (21) may be re-written as:

$$
\frac{Q_{2}^{*}}{\bar{K}-K}<\frac{Q_{2}}{K}<B\left(\frac{S}{K}\right)^{1-\beta}
$$

The condition (24) holds as long as the average productivity of capital is higher in the South than in the North. Returns being constant, the same inequality holds for marginal productivity and returns.

Unskilled workers are paid: $w_{u}^{*}=(1-\beta) B p\left(\frac{\bar{K}-K}{U^{*}}\right)^{\beta}-c A$, skilled workers are paid: $w_{s}^{*}=c A$ and returns to capital are given by: $\rho^{*}=\beta B p\left(\frac{U^{*}}{\bar{K}-K}\right)^{1-\beta}$. Then, the global income generated in the North equals:

$$
I^{*}=c A\left(S^{*}-U^{*}\right)+B p(\bar{K}-K)^{\beta}\left(U^{*}\right)^{1-\beta}
$$

The world income equals:

$$
\bar{I}=A\left[U+c\left(\bar{S}-U^{*}\right)\right]+\beta(B p)^{\frac{1}{\beta}}\left[\frac{1-\beta}{(1+c) A}\right]^{\frac{1}{\beta}-1} K+B p(\bar{K}-K)^{\beta}\left(U^{*}\right)^{1-\beta}
$$


Noting that: $Q_{1}=A(U+c S)-(1-\beta) p Q_{2}$, the equilibrium condition (13) becomes:

$$
\begin{aligned}
(1-\gamma)\left[A(U+c S)+Q_{1}^{*}\right]= & (1-\beta+\beta \gamma) p Q_{2}+\gamma p Q_{2}^{*} \\
\Leftrightarrow(1-\gamma) A\left[U+c\left(\bar{S}-U^{*}\right)\right]= & (1-\beta+\beta \gamma)(B p)^{\frac{1}{\beta}}\left[\frac{1-\beta}{(1+c) A}\right]^{\frac{1}{\beta}-1} K \\
& +\gamma B p(\bar{K}-K)^{\beta}\left(U^{*}\right)^{1-\beta}
\end{aligned}
$$

This equation has no explicit solution. However, as the left hand side is positive and does not depend upon $p$, while the right hand side increases from zero to infinity when $p$ increases from zero to infinity, there is always an equilibrium price and this price is unique. This solution depends upon the capital invested in the South, $K$, and the number of unskilled workers employed in the South, $U^{*}$. Thus, the price can be written: $p=p\left(K, U^{*}\right)$.

At international equilibrium, the conditions (14) and (16) are met. The former may be written as:

$$
\tau=\rho-\rho^{*}=\beta B p\left(K, U^{*}\right)\left\{\left[\frac{(1-\beta) B p\left(K, U^{*}\right)}{(1+c) A}\right]^{\frac{1}{\beta}-1}-\left(\frac{U^{*}}{\bar{K}-K}\right)^{1-\beta}\right\}
$$

so that:

$$
K=\bar{K}-U^{*}\left\{\left[\frac{(1+c) A}{(1-\beta) B p\left(K, U^{*}\right)}\right]^{\frac{1}{\beta}}-\left[\frac{\beta B p\left(K, U^{*}\right)}{\tau}\right]^{\frac{1}{1-\beta}}\right\}
$$

The later becomes:

$$
\mu_{u}=w_{u}^{*}-w_{u}=(1-\beta) B p\left(K, U^{*}\right)\left(\frac{\bar{K}-K}{U^{*}}\right)^{\beta}-(1+c) A
$$

which leads to:

$$
U^{*}=\left[\frac{(1-\beta) B p\left(K, U^{*}\right)}{\mu_{u}+(1+c) A}\right]^{\frac{1}{\beta}}(\bar{K}-K)
$$

The wages of skilled workers in the South and in the North are given by: $w_{s}=w_{s}^{*}=c A$. As they are identical in both countries, there is no skilled migration from the North to the South: $S=S_{0}$ and $S^{*}=S_{0}^{*}$.

\subsubsection{Marginal change in the risk premium or in the migration cost for unskilled workers}

At equilibrium, we look at what happens to the factor allocation between countries when either $\tau$ or $\mu_{u}$ increases at the margin. Calculations are presented in appendix, Section A.4 and lead to the results presented in Table 3.

\begin{tabular}{c|cc} 
& $\frac{d \tau}{\tau}$ & $\frac{d \mu_{u}}{\mu_{u}+(1+c) A}$ \\
\hline$\frac{d K}{K}$ & - & + \\
$\frac{d U^{*}}{U^{*}}$ & + & -
\end{tabular}

Table 3: Changes induced by a marginal increase in $\tau$ or $\mu_{u}$ (small investment case) 
A marginal increase in the risk premium implies that capitalists expect higher returns in the North than in the South, such that: $\tau>\rho-\rho^{*}$. Thus, more capital remains in the North to the detriment of the South $\left(\frac{d K}{K}<0\right)$. In the North, a larger stock of capital implies a higher demand for labor by the industrial sector. Unskilled labor being scarce in this country, the wages of unskilled workers increase in the North, attracting new unskilled workers from the South $\left(\frac{d U^{*}}{U^{*}}>0\right)$.

A marginal increase in the migration cost for unskilled workers implies that Southern unskilled workers have less incentives to go North, such that: $\mu_{u}>w_{u}^{*}-w_{u}$. In that case, the stock of unskilled labor increases in the South to the detriment of the North $\left(\frac{d U^{*}}{U^{*}}<0\right)$. In the North, the lower supply of unskilled Southern workers implies that unskilled workers get higher wages, depressing the returns to capital. Investing in the South becomes a more attractive option for capitalists, consequently the capital stock increases in the South to the detriment of the North $\left(\frac{d K}{K}>0\right)$.

Changes in the capital and unskilled labor allocation between countries have no consequence on the allocation of skilled labor across sectors. The wages of skilled workers remain equal across countries $\left(w_{s}=w_{s}^{*}=c A\right)$, thereby skilled workers have no incentive to migrate $\left(d S=d S^{*}=0\right)$.

Thus, changes in the risk premium and in the migration cost of unskilled workers both lead to capital flows and unskilled migration moving in opposite directions. For instance, a decrease in the risk premium leads to an increase in North-South capital flows. This, in turn, leads to a decrease in South-North unskilled migration. Then, we can conclude that FDI and unskilled migration are substitutes.

\section{Concluding remarks}

In this paper, we have presented a theoretical model that reconciles the standard trade theory with a number of empirical studies on FDI and migration taking place between developed and developing countries. Our approach allows us to evidence both substitution and complementarity between factor flows in a single trade model. Analyzing both directions of the nexus, we find that capital and unskilled labor flows are substitutes, and that capital and skilled labor flows are complements.

The intuition is the following: Capitalists need to combine their capital with both unskilled and skilled workers. When located in the North where unskilled workers are scarce, they attract unskilled migrants from the South; when located in the South where skilled workers are scarce, they attract skilled migrants from the North. Such a North-South migration can be akin to Northern managers and technicians sent to control the plants in the foreign country. Conversely, we show that the movement of people across borders can also lead to the relocation of a number of firms.

Our results corroborate empirical studies showing that unskilled migration and FDI toward migrants' origin countries are negatively related (El Yaman et al., 2007; Kugler and Rapoport, 
2007) and that skilled migration and FDI from migrants' origin countries are positively related (Docquier and Lodigiani, 2010; Foad, 2012; Gheasi et al., 2013; Hoxhaj et al., 2015).

However, our model does not explain empirical findings suggesting that skilled migration and FDI toward migrants' origin countries are complements (El Yaman et al., 2007; Kugler and Rapoport, 2007; Javorcik et al., 2011). This empirical result is in line with the literature on migration network effects. To introduce such effects in the modelling of the FDI-migration nexus, one could use the new trade theory that integrates economies of scale and monopolistic competition among firms (Helpman and Krugman, 1985). See Felbermayr et al. (2012) who discuss how such a model can be used to understand the relation between factor flows.

Both types of mechanisms are important to understand the FDI-migration nexus. On the one hand, standard forces evidenced by the international trade theory have virtually been ignored so far. We therefore try to fill this gap, showing that these forces can generate population displacements for work purpose between developed and developing countries. On the other hand, network effects stressed by the empirical literature are better able to explain the link between skilled migration and FDI flowing in opposite directions.

Finally, although our results are quite instructive on the link between capital and labor flows, future theoretical research could try (i) to introduce Ricardian type differences in productivities across countries, (ii) to relax the strict complementarity between unskilled and skilled workers in the production of the industrial good, and (iii) to consider native and foreign workers as imperfect substitutes as research initiated by Peri and Sparber (2009) and Ottaviano et al. (2013) suggests. Such refinements should not change the main results of the model, but could modify their magnitude and thus their precision. This exercise could then allow one to propose a numerical calibration of the model.

With this paper, we contribute to the literature showing that factor flows are highly interdependent, and thereby that migration and commercial policies should be designed together. First, let us consider policy interventions aiming at attracting FDI, which is a potential source of economic growth, particularly for developing countries (Hansen and Rand, 2006). Because capital and skilled labor flows are complements, countries attracting foreign firms should implement policies to answer their demand in skilled labor. In the short run, countries should implement policies supporting the arrival of high skilled workers, and particularly supporting skilled worker transfers that allow multinational enterprises to coordinate their headquarter and their affiliates' operations (Kogut and Zander, 2003; Williams, 2007). In the long run, developing countries should reduce their skilled labor shortage by investing in education in order to increase their stock of human capital.

Then, our results suggest some policy recommendations aiming at regulating migration flows. On the one hand, migration of skilled workers is usually perceived as a loss for origin countries in terms of human capital and educational costs, and as a gain for host countries. ${ }^{6}$ Thus, because capital and skilled labor flows are complements, countries intending to limit the departure of

\footnotetext{
${ }^{6}$ Although the migration of skilled workers is traditionally seen as a problem for source countries, there is a number of positive externalities induced by emigration. For instance, migrants contribute to the development of
} 
skilled workers should implement policies attracting FDI in order to provide them with adequate job opportunities (Bodvarsson and Van den Berg, 2009). ${ }^{7}$

On the other hand, migration of unskilled workers is often seen as positive for the sending country which benefits from remittances (Gamlen, 2008), but perceived as a social burden for developed receiving countries (Goldin et al., 2011). ${ }^{8}$ Since capital and unskilled labor flows are substitutes, receiving countries aiming at regulating the volume of their unskilled immigration could implement pro-active investment policies toward migrants' origin countries.

\section{Acknowledgements}

We thank participants at the 4th annual OECD conference on Immigration in OECD countries (particularly Richard Freeman), at the 2014 Annual Meeting of the ASSET, at the 2014 ETSG, at the 5th International conference on "Economics of global interactions", at the internal seminar of the University Aldo Moro of Bari, and at the EQUIPPE internal seminar for useful comments and discussions. The usual disclaimer applies.

\section{References}

Anwar, S., "Labour supply, foreign investment and welfare in the presence of public infrastructure," Economic Modelling, 2008, 25 (5), 959-967.

Aroca, P. and W. F. Maloney, "Migration, Trade, and Foreign Direct Investment in Mexico," World Bank Economic Review, 2005, 19 (3), 449-472.

Bhattacharya, U. and P. Groznik, "Melting pot or salad bowl: Some evidence from U.S. investments abroad," Journal of Financial Markets, 2008, 11 (3), 228-258.

Bodvarsson, Ö. B. and H. Van den Berg, The economics of immigration: theory and policy, Springer Verlag, 2009.

Buch, C. M., J. Kleinert, and F. Toubal, "Where enterprises lead, people follow? Links between migration and FDI in Germany," European Economic Review, 2006, 50 (8), 2017-2036.

\footnotetext{
their origin countries thanks to their investments and remittances. Gibson and McKenzie (2011) show that high skilled migrants are remitting about as much as their absence costs to their origin country.

${ }^{7}$ Bodvarsson and Van den Berg (2009) review the determinants of the brain drain. One reason for which skilled individuals emigrate is that they see little opportunities in their home country, where there is a lack of demand for skills and often an inefficient labor market. Consequently, they are not well valued nor well paid in their home countries.

${ }^{8}$ Developing countries are now aware that emigration may induce positive gains. Some countries are starting to elaborate policies oriented toward their diaspora, for instance, policies easing remittances and investments from emigrants (Gamlen, 2008). However, despite evidence that immigration has a positive or neutral effect on host societies, developing countries perceive it "[...] as something to be managed, [...] a cost to be minimized rather than an opportunity to be embraced" (Goldin et al., 2011).
} 
D'Agosto, E., N. Solferino, and G. Tria, "Does FDI affect migration flows? The role of human capital," Migration Letters, 2013, 10 (3), 359-368.

Davis, D. R. and D. E. Weinstein, "Technological superiority and the losses from migration," Working Paper Series 8971, National Bureau of Economic Research May 2002.

De Simone, G. and M. Manchin, "Outward Migration and Inward FDI: Factor Mobility between Eastern and Western Europe," Review of International Economics, 2012, 20 (3), 600615 .

Docquier, F. and E. Lodigiani, "Skilled migration and business networks," Open Economies Review, 2010, 21 (4), 565-588.

El Yaman, S., M. Kugler, and H. Rapoport, "Migrations et investissements directs étrangers dans l'espace européen (UE-15)," Revue Économique, 2007, 58 (3), 725-733.

Federici, D. and M. Giannetti, "Temporary migration and foreign direct investment," Open Economies Review, 2010, 21 (2), 293-308.

Felbermayr, G., V. Grossmann, and W. Kohler, "Migration, International Trade and Capital Formation: Cause or Effect?," Discussion Paper Series 6975, IZA 2012.

Flatters, F., "Commodity Price Equilization: A Note on Factor Mobility and Trade," American Economic Review, 1972, 62 (3), 473-476.

Foad, H., "FDI and immigration: a regional analysis," The Annals of Regional Science, 2012, 49 (1), 237-259.

Gamlen, A., "Why Engage Diasporas?," Working Paper 63, ESRC Centre on Migration, Policy and Society, University of Oxford 2008.

Gao, T., "Ethnic Chinese networks and international investment: evidence from inward FDI in China," Journal of Asian Economics, 2003, 14 (4), 611-629.

Gheasi, M., P. Nijkamp, and P. Rietveld, "Migration and foreign direct investment: education matters," Annals of Regional Science, 2013, 51 (1), 73-87.

Gibson, J. and D. McKenzie, "Eight Questions about Brain Drain," Journal of Economic Perspectives, 2011, 25 (3), 107-128.

Goldin, I., G. Cameron, and M. Balarajan, Exceptional people: How migration shaped our world and will define our future., Princeton University Press, 2011.

Hansen, H. and J. Rand, "On the Causal Links Between FDI and Growth in Developing Countries," World Economy, 2006, 29 (1), 21-41. 
Heckscher, E. F., "The effect of foreign trade on the distribution of income," Ekonomisk Tidskriff, 1919, pp. 497-512. Translated as chapter 13 in American Economic Association, Readings in the Theory of International Trade, Philadelphia: Blakiston, 1949, 272-300.

Helpman, E. and P. Krugman, Market Structure and Foreign Trade, Cambridge Massachusetts, 1985.

Hoxhaj, R., L. Marchal, and A. Seric, "FDI and Migration of Skilled Workers Towards Developing Countries: Firm-Level Evidence from Sub-Saharan Africa," Journal of African Economies, 2015.

Javorcik, B. S., Ç. Özden, M. Spatareanu, and C. Neagu, "Migrant networks and foreign direct investment," Journal of Development Economics, 2011, 94 (2), 231-241.

Kogut, B. and U. Zander, "Knowledge of the firm and the evolutionary theory of the multinational corporation," Journal of International Business Studies, 2003, 34 (6), 516-529.

Kugler, M. and H. Rapoport, "International labor and capital flows: Complements or substitutes?," Economics Letters, 2007, 94 (2), 155-162.

Laczko, F. and T. Brian, "North-South migration: A different look at the migration and development debate," International Organization for Migration, Migration Policy Practice, JuneJuly 2013.

Mundell, R. A., "International trade and factor mobility," American Economic Review, June 1957, $47(3), 321-335$.

Ohlin, B. G., Interregional and international trade, Harvard University Press, 1933.

Ottaviano, G. I. P., G. Peri, and G. C. Wright, "Immigration, Offshoring, and American Jobs," American Economic Review, 2013, 103 (5), 1925-1959.

Peri, G. and C. Sparber, "Task Specialization, Immigration, and Wages," American Economic Journal: Applied Economics, 2009, 1 (3), 135-169.

Ricketts, E., "U.S. Investment and Immigration from the Caribbean," Social Problems, 1987, 34 (4), 374-387.

Sanderson, M. R. and J. Kentor, "Foreign Direct Investment and International Migration: A Cross-National Analysis of Less-Developed Countries, 1985-2000," International Sociology, 2008, 23 (4), 514-539.

Sassen, S., The Mobility of Labor and Capital, Cambridge University Press, 1988.

Sauvant, K. P., P. Mallampally, and P. Economou, "Foreign direct investment and international migration," Transnational Corporations, 1993, 2 (1), 33-69. 
Tong, S. Y., "Ethnic Networks in FDI and the Impact of Institutional Development," Review of Development Economics, 2005, 9 (4), 563-580.

Venables, A. J., "Fragmentation and multinational production," European Economic Review, 1999, 43 (4-6), 935-945.

Wang, M., M. C. S. Wong, and J. Granato, "The Effect of Foreign Direct Investment on International Migration: Does Education Matter?," World Economy, 2013, 36 (5), 537-562.

Williams, A. M., "International labour migration and tacit knowledge transactions: a multilevel perspective," Global Networks, 2007, 7 (1), 29-50.

Wong, K.-Y., "Are International Capital Movement and International Labor Migration Substitutes under National Externality?," in R. J. Langhammer and F. Foders, eds., Labor Mobility and the World Economy, Springer Berlin Heidelberg, 2006, pp. 111-139. 


\section{A Appendix}

\section{A.1 Single country (interior solution)}

We assume that both factors are employed in the non-capitalist sector, so that $u_{1}>0$ and $s_{1}>0$. Combining equations (3), (4) and (6), we obtain:

$$
l=\frac{(1-\beta) p}{(1+c) A}
$$

Then, using equations (2), (5) and (9), we obtain:

$$
\begin{aligned}
k & =B^{-\frac{1}{\beta}} l^{1-\frac{1}{\beta}} \\
\rho & =\beta p k^{-1}=\beta B^{\frac{1}{\beta}} p l^{\frac{1}{\beta}-1} \\
Q_{2} & =k^{-1} K=K B^{\frac{1}{\beta}} l^{\frac{1}{\beta}-1}
\end{aligned}
$$

where $l$ is given by equation (26). The wages are given by equations (3) and (4). Combining (26) with the equilibrium conditions (7) and (8) we get:

$$
\begin{aligned}
& U=u_{1} Q_{1}+l Q_{2}=u_{1} Q_{1}+K B^{\frac{1}{\beta}} l^{\frac{1}{\beta}} \\
& S=s_{1} Q_{1}+l Q_{2}=s_{1} Q_{1}+K B^{\frac{1}{\beta}} l^{\frac{1}{\beta}}
\end{aligned}
$$

Using the production function (1):

$$
U+c S=\left(u_{1}+c s_{1}\right) Q_{1}+(1+c) K(B l)^{\frac{1}{\beta}}=A^{-1} Q_{1}+(1+c) K(B l)^{\frac{1}{\beta}}
$$

hence:

$$
Q_{1}=A\left[U+c S-(1+c) K(B l)^{\frac{1}{\beta}}\right]
$$

and:

$$
\begin{aligned}
& u_{1}=\frac{U-K(B l)^{\frac{1}{\beta}}}{Q_{1}}=\frac{U-K(B l)^{\frac{1}{\beta}}}{A\left[U+c S-(1+c) K(B l)^{\frac{1}{\beta}}\right]} \\
& s_{1}=\frac{S-K(B l)^{\frac{1}{\beta}}}{Q_{1}}=\frac{S-K(B l)^{\frac{1}{\beta}}}{A\left[U+c S-(1+c) K(B l)^{\frac{1}{\beta}}\right]}
\end{aligned}
$$

The conditions $u_{1}>0$ and $s_{1}>0$ imply:

$$
K(B l)^{\frac{1}{\beta}}=K\left[\frac{(1-\beta) B p}{(1+c) A}\right]^{\frac{1}{\beta}}<\min (U, S)
$$

\section{A.2 Single country (corner solutions)}

Let us first look at the case $u_{1}>0$ and $s_{1}=0$, which happens when:

$$
S<K(B l)^{\frac{1}{\beta}}=K\left[\frac{(1-\beta) B p}{(1+c) A}\right]^{\frac{1}{\beta}}<U
$$


Then, skilled labor is scarce enough for being employed in the capitalist sector only; the noncapitalist sector employs unskilled labor only. If the wage of unskilled workers is still given by (3), the fact that skilled workers are no longer employed by the non-capitalist sector implies that their wage is no longer given by (4). Knowing that $s_{1}=0$, and using equations (8) and (7), we get:

$$
\begin{aligned}
l Q_{2} & =S \\
u_{1} Q_{1} & =U-l Q_{2}=U-S
\end{aligned}
$$

Then, using the production function (1) and the fact that $s_{1}=0$, we find:

$$
Q_{1}=A\left(u_{1}+c s_{1}\right) Q_{1}=A u_{1} Q_{1}=A(U-S)
$$

and combining equations (9), (2) and (8):

$$
\begin{aligned}
Q_{2} & =B K^{\beta} l Q_{2}^{1-\beta}=B K^{\beta} S^{1-\beta} \\
k & =\frac{K}{Q_{2}}=B^{-1}\left(\frac{K}{S}\right)^{1-\beta} \\
l & =\frac{S}{Q_{2}}=B^{-1}\left(\frac{S}{K}\right)^{\beta}
\end{aligned}
$$

Last, using (3), (5) and (6), we get the wage of skilled workers and the returns to capital:

$$
\begin{aligned}
w_{s} & =\frac{(1-\beta) p}{l}-w_{u}=(1-\beta) B p\left(\frac{K}{S}\right)^{\beta}-A>c A \\
\rho & =\beta p k^{-1}=\beta B p\left(\frac{S}{K}\right)^{1-\beta}
\end{aligned}
$$

Let us now look at the case $u_{1}=0$ and $s_{1}>0$, which happens when:

$$
U<K(B l)^{\frac{1}{\beta}}=K\left[\frac{(1-\beta) B p}{(1+c) A}\right]^{\frac{1}{\beta}}<S
$$

Now, unskilled labor is scarce enough for being employed in the capitalist sector only; the noncapitalist sector employs skilled labor only. The wage of skilled workers is still given by equation (4), but unskilled workers are no longer employed by the non-capitalist sector, which implies that their wage is no longer given by (3). Knowing that $u_{1}=0$, and using (8) and (7), we get:

$$
\begin{aligned}
l Q_{2} & =U \\
s_{1} Q_{1} & =S-l Q_{2}=S-U
\end{aligned}
$$

Then, using the production function (1) and the fact that $u_{1}=0$, we find:

$$
Q_{1}=A\left(u_{1}+c s_{1}\right) Q_{1}=A c s_{1} Q_{1}=A c(S-U)
$$


and combining equations (9), (2) and (8):

$$
\begin{aligned}
Q_{2} & =B K^{\beta} l Q_{2}^{1-\beta}=B K^{\beta} U^{1-\beta} \\
k & =\frac{K}{Q_{2}}=B^{-1}\left(\frac{K}{U}\right)^{1-\beta} \\
l & =\frac{U}{Q_{2}}=B^{-1}\left(\frac{U}{K}\right)^{\beta}
\end{aligned}
$$

Last, using (4) and (5), we get the wage of skilled workers and the returns to capital:

$$
\begin{aligned}
w_{u} & =\frac{(1-\beta) p}{l}-w_{s}=(1-\beta) B p\left(\frac{K}{U}\right)^{\beta}-c A>A \\
\rho & =\beta p k^{-1}=\beta B p\left(\frac{U}{K}\right)^{1-\beta}
\end{aligned}
$$

\section{A.3 Impact of a risk premium and migration costs variation on the factor allocation (large transfer case)}

At equilibrium, we look at the impact of a change in the risk premium and migration costs on the factor allocation among countries, when capital is worldly abundant and is invested in both countries $\left(K>0\right.$ and $\left.K^{*}>0\right)$, case initially developed in Section 4.3.

Let us remind the equilibrium conditions:

$$
\begin{aligned}
\tau & =\beta B p\left[\left(\frac{S}{K}\right)^{1-\beta}-\left(\frac{U^{*}}{\bar{K}-K}\right)^{1-\beta}\right]=\beta p\left(\frac{Q_{2}}{K}-\frac{Q_{2}^{*}}{\bar{K}-K}\right) \\
\mu_{s} & =(1-\beta) B p\left(\frac{K}{S}\right)^{\beta}-(1+c) A \\
\mu_{u} & =(1-\beta) B p\left(\frac{\bar{K}-K}{U^{*}}\right)^{\beta}-(1+c) A
\end{aligned}
$$

where the world price of the industrial good is:

$$
p=\frac{1-\gamma}{\gamma} \frac{Q_{1}+Q_{1}^{*}}{Q_{2}+Q_{2}^{*}}=\frac{1-\gamma}{\gamma} \frac{A\left[\bar{U}+c \bar{S}-(1+c)\left(U^{*}+S\right)\right]}{B\left[K^{\beta} S^{1-\beta}+(\bar{K}-K)^{\beta}\left(U^{*}\right)^{1-\beta}\right]}
$$

The logarithmic derivative of the price is:

$$
\begin{aligned}
\frac{d p}{p} & =\frac{d\left(Q_{1}+Q_{1}^{*}\right)}{Q_{1}+Q_{1}^{*}}-\frac{d\left(Q_{2}+Q_{2}^{*}\right)}{Q_{2}+Q_{2}^{*}} \\
& =-\frac{A(1+c)\left(d S+d U^{*}\right)}{Q_{1}+Q_{1}^{*}}-\frac{Q_{2}\left[\beta \frac{d K}{K}+(1-\beta) \frac{d S}{S}\right]+Q_{2}^{*}\left[(1-\beta) \frac{d U^{*}}{U^{*}}-\beta \frac{d K}{K-K}\right]}{Q_{2}+Q_{2}^{*}} \\
& =-\frac{A(1+c)}{Q_{1}+Q_{1}^{*}}\left(d S+d U^{*}\right)-\frac{\beta Q_{2}}{Q_{2}+Q_{2}^{*}} \frac{d K}{K}-\frac{(1-\beta) Q_{2}}{Q_{2}+Q_{2}^{*}} \frac{d S}{S}-\frac{(1-\beta) Q_{2}^{*}}{Q_{2}+Q_{2}^{*}} \frac{d U^{*}}{U^{*}}+\frac{\beta Q_{2}^{*}}{Q_{2}+Q_{2}^{*}} \frac{d K}{\bar{K}-K} \\
& =-\frac{A(1+c)}{Q_{1}+Q_{1}^{*}}\left(d S+d U^{*}\right)+\frac{\beta}{Q_{2}+Q_{2}^{*}}\left(\frac{K Q_{2}^{*}}{\bar{K}-K}-Q_{2}\right) \frac{d K}{K}-\frac{(1-\beta) Q_{2}}{Q_{2}+Q_{2}^{*}} \frac{d S}{S}-\frac{(1-\beta) Q_{2}^{*}}{Q_{2}+Q_{2}^{*}} \frac{d U^{*}}{U^{*}} \\
& =B_{K} \frac{d K}{K}-B_{S} \frac{d S}{S}-B_{U} \frac{d U^{*}}{U^{*}}
\end{aligned}
$$


with:

$$
\begin{aligned}
B_{K} & =-\frac{\beta K}{Q_{2}+Q_{2}^{*}}\left(\frac{Q_{2}}{K}-\frac{Q_{2}^{*}}{\bar{K}-K}\right)=-\frac{\tau K / p}{Q_{2}+Q_{2}^{*}}<0 \\
B_{S} & =\frac{A(1+c)}{Q_{1}+Q_{1}^{*}} S+\frac{(1-\beta) Q_{2}}{Q_{2}+Q_{2}^{*}}>0 \\
B_{U} & =\frac{A(1+c)}{Q_{1}+Q_{1}^{*}} U^{*}+\frac{(1-\beta) Q_{2}^{*}}{Q_{2}+Q_{2}^{*}}>0
\end{aligned}
$$

and:

$$
\begin{aligned}
B_{U}+B_{S} & =\frac{A(1+c)\left(S+U^{*}\right)}{Q_{1}+Q_{1}^{*}}+1-\beta \\
& =\frac{1}{\frac{\bar{U}+c \bar{S}}{(1+c)\left(U^{*}+S\right)}-1}+1-\beta \\
& =\frac{1}{1-(1+c) \frac{S+U^{*}}{\bar{U}+c \bar{S}}}-\beta
\end{aligned}
$$

The logarithmic derivatives of the equilibrium conditions are:

$$
\begin{aligned}
\frac{d \tau}{\tau} & =\frac{d p}{p}+(1-\beta) \frac{\frac{Q_{2}}{K}\left(\frac{d S}{S}-\frac{d K}{K}\right)-\frac{Q_{2}^{*}}{\bar{K}-K}\left(\frac{d U^{*}}{U^{*}}+\frac{d K}{\bar{K}-K}\right)}{\frac{Q_{2}}{K}-\frac{Q_{2}^{*}}{\bar{K}-K}} \\
& =\frac{d p}{p}-A_{K} \frac{d K}{K}+A_{S} \frac{d S}{S}-A_{U} \frac{d U^{*}}{U^{*}} \\
\frac{d \mu_{s}}{\mu_{s}+(1+c) A} & =\frac{d p}{p}+\beta\left(\frac{d K}{K}-\frac{d S}{S}\right) \\
\frac{d \mu_{u}}{\mu_{u}+(1+c) A} & =\frac{d p}{p}-\beta\left(\frac{d K}{\bar{K}-K}+\frac{d U^{*}}{U^{*}}\right)
\end{aligned}
$$

where:

$$
\begin{aligned}
& A_{K}=(1-\beta) \frac{\frac{Q_{2}}{K}+\frac{K}{K-K} \frac{Q_{2}^{*}}{K-K}}{\frac{Q_{2}}{K}-\frac{Q_{2}^{*}}{\bar{K}-K}}=A_{S}+\frac{K}{\bar{K}-K} A_{U}>0 \\
& A_{S}= \frac{(1-\beta) \frac{Q_{2}}{K}}{\frac{Q_{2}}{K}-\frac{Q_{2}^{*}}{K-K}}=(1-\beta) \frac{\beta p}{\tau} \frac{Q_{2}}{K}>0 \\
& A_{U}=\frac{(1-\beta) \frac{Q_{2}^{*}}{K-K}}{\frac{Q_{2}}{K}-\frac{Q_{2}^{*}}{K-K}}=(1-\beta) \frac{\beta p}{\tau} \frac{Q_{2}^{*}}{\bar{K}-K}>0
\end{aligned}
$$

Combining the last two equilibrium conditions, we find:

$$
\frac{d K}{K}=\frac{\bar{K}-K}{\bar{K}}\left(\frac{d S}{S}-\frac{d U^{*}}{U^{*}}\right)+\frac{\bar{K}-K}{\beta \bar{K}}\left[\frac{d \mu_{s}}{\mu_{s}+(1+c) A}-\frac{d \mu_{u}}{\mu_{u}+(1+c) A}\right]
$$


Then:

$$
\begin{aligned}
\frac{d \tau}{\tau}= & \frac{d p}{p}-\frac{\bar{K}-K}{\beta \bar{K}} A_{K}\left[\frac{d \mu_{s}}{\mu_{s}+(1+c) A}-\frac{d \mu_{u}}{\mu_{u}+(1+c) A}\right] \\
& +\left(A_{S}-\frac{\bar{K}-K}{\bar{K}} A_{K}\right) \frac{d S}{S}+\left(\frac{\bar{K}-K}{\bar{K}} A_{K}-A_{U}\right) \frac{d U^{*}}{U^{*}} \\
\frac{d \mu_{s}}{\mu_{s}+(1+c) A}= & \frac{d p}{p}-\beta\left(\frac{K}{\bar{K}} \frac{d S}{S}+\frac{\bar{K}-K}{\bar{K}} \frac{d U^{*}}{U^{*}}\right)+\frac{\bar{K}-K}{\bar{K}}\left[\frac{d \mu_{s}}{\mu_{s}+(1+c) A}-\frac{d \mu_{u}}{\mu_{u}+(1+c) A}\right] \\
\frac{d \mu_{u}}{\mu_{u}+(1+c) A}= & \frac{d p}{p}-\beta\left(\frac{K}{\bar{K}} \frac{d S}{S}+\frac{\bar{K}-K}{\bar{K}} \frac{d U^{*}}{U^{*}}\right)-\frac{K}{\bar{K}}\left[\frac{d \mu_{s}}{\mu_{s}+(1+c) A}-\frac{d \mu_{u}}{\mu_{u}+(1+c) A}\right]
\end{aligned}
$$

where noting that $A_{S}-A_{U}=1-\beta$ :

$$
\begin{aligned}
& A_{S}-\frac{\bar{K}-K}{\bar{K}} A_{K}=A_{S}-\frac{\bar{K}-K}{\bar{K}}\left(A_{S}+\frac{K}{\bar{K}-K} A_{U}\right)=\frac{K}{\bar{K}}\left(A_{S}-A_{U}\right)=(1-\beta) \frac{K}{\bar{K}} \\
& \frac{\bar{K}-K}{\bar{K}} A_{K}-A_{U}=\frac{\bar{K}-K}{\bar{K}}\left(A_{S}+\frac{K}{\bar{K}-K} A_{U}\right)-A_{U}=\frac{\bar{K}-K}{\bar{K}}\left(A_{S}-A_{U}\right)=(1-\beta) \frac{\bar{K}-K}{\bar{K}}
\end{aligned}
$$

Then, by reducing the last two equations to the same final equation, we find:

$$
\begin{aligned}
\frac{d \tau}{\tau}= & \frac{d p}{p}+(1-\beta) \frac{K}{\bar{K}} \frac{d S}{S}+(1-\beta) \frac{\bar{K}-K}{\bar{K}} \frac{d U^{*}}{U^{*}} \\
& -\frac{\bar{K}-K}{\beta \bar{K}} A_{K}\left[\frac{d \mu_{s}}{\mu_{s}+(1+c) A}-\frac{d \mu_{u}}{\mu_{u}+(1+c) A}\right] \\
\beta\left(\frac{K}{\bar{K}} \frac{d S}{S}+\frac{\bar{K}-K}{\bar{K}} \frac{d U^{*}}{U^{*}}\right)= & \frac{d p}{p}-\frac{K}{\bar{K}} \frac{d \mu_{s}}{\mu_{s}+(1+c) A}-\frac{\bar{K}-K}{\bar{K}} \frac{d \mu_{u}}{\mu_{u}+(1+c) A}
\end{aligned}
$$

or equivalently:

$$
\begin{aligned}
(1-\beta)\left(\frac{K}{\bar{K}} \frac{d S}{S}+\frac{\bar{K}-K}{\bar{K}} \frac{d U^{*}}{U^{*}}\right) & =\frac{d \tau}{\tau}-\frac{d p}{p}+\frac{\bar{K}-K}{\beta \bar{K}} A_{K}\left[\frac{d \mu_{s}}{\mu_{s}+(1+c) A}-\frac{d \mu_{u}}{\mu_{u}+(1+c) A}\right] \\
\beta\left(\frac{K}{\bar{K}} \frac{d S}{S}+\frac{\bar{K}-K}{\bar{K}} \frac{d U^{*}}{U^{*}}\right) & =\frac{d p}{p}-\frac{K}{\bar{K}} \frac{d \mu_{s}}{\mu_{s}+(1+c) A}-\frac{\bar{K}-K}{\bar{K}} \frac{d \mu_{u}}{\mu_{u}+(1+c) A}
\end{aligned}
$$

so that:

$$
\begin{aligned}
\frac{K}{\bar{K}} \frac{d S}{S}+\frac{\bar{K}-K}{\bar{K}} \frac{d U^{*}}{U^{*}} & =\frac{d \tau}{\tau}+\left(\frac{\bar{K}-K}{\beta \bar{K}} A_{K}-\frac{K}{\bar{K}}\right) \frac{d \mu_{s}}{\mu_{s}+(1+c) A}-\frac{\bar{K}-K}{\beta \bar{K}}\left(A_{K}+\beta\right) \frac{d \mu_{u}}{\mu_{u}+(1+c) A} \\
\frac{d p}{p} & =\beta \frac{d \tau}{\tau}+\left[\frac{\bar{K}-K}{\bar{K}} A_{K}+(1-\beta) \frac{K}{\bar{K}}\right] \frac{d \mu_{s}}{\mu_{s}+(1+c) A}+\left(1-\beta-A_{K}\right) \frac{\bar{K}-K}{\bar{K}} \frac{d \mu_{u}}{\mu_{u}+(1+c) A} \\
& =\beta \frac{d \tau}{\tau}+A_{S} \frac{d \mu_{s}}{\mu_{s}+(1+c) A}-A_{U} \frac{d \mu_{u}}{\mu_{u}+(1+c) A}
\end{aligned}
$$


Moreover:

$$
\begin{aligned}
\frac{d p}{p}= & B_{K} \frac{d K}{K}-B_{S} \frac{d S}{S}-B_{U} \frac{d U^{*}}{U^{*}} \\
= & B_{K}\left\{\frac{\bar{K}-K}{\bar{K}}\left(\frac{d S}{S}-\frac{d U^{*}}{U^{*}}\right)+\frac{\bar{K}-K}{\beta \bar{K}}\left[\frac{d \mu_{s}}{\mu_{s}+(1+c) A}-\frac{d \mu_{u}}{\mu_{u}+(1+c) A}\right]\right\} \\
& -B_{S} \frac{d S}{S}-B_{U} \frac{d U^{*}}{U^{*}} \\
= & \frac{\bar{K}-K}{\beta \bar{K}} B_{K}\left[\frac{d \mu_{s}}{\mu_{s}+(1+c) A}-\frac{d \mu_{u}}{\mu_{u}+(1+c) A}\right]+\left(\frac{\bar{K}-K}{\bar{K}} B_{K}-B_{S}\right) \frac{d S}{S} \\
& -\left(\frac{\bar{K}-K}{\bar{K}} B_{K}+B_{U}\right) \frac{d U^{*}}{U^{*}}
\end{aligned}
$$

and then:

$$
\begin{aligned}
\left(\frac{\bar{K}-K}{\bar{K}} B_{K}+B_{U}\right) \frac{d U^{*}}{U^{*}}-\left(\frac{\bar{K}-K}{\bar{K}} B_{K}-B_{S}\right) \frac{d S}{S}= & \frac{\bar{K}-K}{\beta \bar{K}} B_{K}\left[\frac{d \mu_{s}}{\mu_{s}+(1+c) A}-\frac{d \mu_{u}}{\mu_{u}+(1+c) A}\right]-\frac{d p}{p} \\
= & \frac{\bar{K}-K}{\beta \bar{K}} B_{K}\left[\frac{d \mu_{s}}{\mu_{s}+(1+c) A}-\frac{d \mu_{u}}{\mu_{u}+(1+c) A}\right] \\
& -\beta \frac{d \tau}{\tau}-A_{S} \frac{d \mu_{s}}{\mu_{s}+(1+c) A}+A_{U} \frac{d \mu_{u}}{\mu_{u}+(1+c) A} \\
= & -\beta \frac{d \tau}{\tau}+\left(\frac{\bar{K}-K}{\beta \bar{K}} B_{K}-A_{S}\right) \frac{d \mu_{s}}{\mu_{s}+(1+c) A} \\
& +\left(A_{U}-\frac{\bar{K}-K}{\beta \bar{K}} B_{K}\right) \frac{d \mu_{u}}{\mu_{u}+(1+c) A}
\end{aligned}
$$

so that:

$$
\begin{aligned}
& \frac{K}{\bar{K}} \frac{d S}{S}+\frac{\bar{K}-K}{\bar{K}} \frac{d U^{*}}{U^{*}}=\frac{d \tau}{\tau}+\left(\frac{\bar{K}-K}{\beta \bar{K}} A_{K}-\frac{K}{\bar{K}}\right) \frac{d \mu_{s}}{\mu_{s}+(1+c) A} \\
&-\frac{\bar{K}-K}{\beta \bar{K}}\left(A_{K}+\beta\right) \frac{d \mu_{u}}{\mu_{u}+(1+c) A} \\
&\left(B_{S}-\frac{\bar{K}-K}{\bar{K}} B_{K}\right) \frac{d S}{S}+\left(\frac{\bar{K}-K}{\bar{K}} B_{K}+B_{U}\right) \frac{d U^{*}}{U^{*}}=-\beta \frac{d \tau}{\tau}+\left(\frac{\bar{K}-K}{\beta \bar{K}} B_{K}-A_{S}\right) \frac{d \mu_{s}}{\mu_{s}+(1+c) A} \\
&+\left(A_{U}-\frac{d \mu_{u}}{\beta \bar{K}} B_{K}\right) \frac{d}{\mu_{u}+(1+c) A}
\end{aligned}
$$

or equivalently:

$$
\Omega\left[\begin{array}{c}
\frac{d S}{S} \\
\frac{d U^{*}}{U^{*}}
\end{array}\right]=\left[\begin{array}{ccc}
1 & \frac{\bar{K}-K}{\beta \bar{K}} A_{K}-\frac{K}{\bar{K}} & -\frac{\bar{K}-K}{\beta \bar{K}}\left(A_{K}+\beta\right) \\
-\beta & \frac{\bar{K}-K}{\beta \bar{K}} B_{K}-A_{S} & A_{U}-\frac{\bar{K}-K}{\beta \bar{K}} B_{K}
\end{array}\right]\left[\begin{array}{c}
\frac{d \tau}{\tau} \\
\frac{d \mu_{s}}{\mu_{s}+(1+c) A} \\
\frac{d \mu_{u}}{\mu_{u}+(1+c) A}
\end{array}\right]
$$

where:

$$
\Omega=\left[\begin{array}{cc}
\frac{K}{\bar{K}} & \frac{\bar{K}-K}{\bar{K}} \\
B_{S}-\frac{\bar{K}-K}{\bar{K}} B_{K} & \frac{\bar{K}-K}{\bar{K}} B_{K}+B_{U}
\end{array}\right]
$$

The determinant of $\Omega$ is:

$$
\begin{aligned}
\Delta & =\frac{K}{\bar{K}}\left(\frac{\bar{K}-K}{\bar{K}} B_{K}+B_{U}\right)-\frac{\bar{K}-K}{\bar{K}}\left(B_{S}-\frac{\bar{K}-K}{\bar{K}} B_{K}\right) \\
& =\frac{\bar{K}-K}{\bar{K}}\left(B_{K}-B_{S}\right)+\frac{K}{\bar{K}} B_{U}
\end{aligned}
$$


Then:

$\left[\begin{array}{c}\frac{d S}{S} \\ \frac{d U^{*}}{U^{*}}\end{array}\right]=\frac{1}{\Delta}\left[\begin{array}{cc}\frac{\bar{K}-K}{\bar{K}} B_{K}+B_{U} & -\frac{\bar{K}-K}{\bar{K}} \\ \frac{\bar{K}-K}{\bar{K}} B_{K}-B_{S} & \frac{K}{\bar{K}}\end{array}\right]\left[\begin{array}{ccc}1 & \frac{\bar{K}-K}{\beta \bar{K}} A_{K}-\frac{K}{\bar{K}} & -\frac{\bar{K}-K}{\beta \bar{K}}\left(A_{K}+\beta\right) \\ -\beta & \frac{\bar{K}-K}{\beta \bar{K}} B_{K}-A_{S} & A_{U}-\frac{\bar{K}-K}{\beta \bar{K}} B_{K}\end{array}\right]\left[\begin{array}{c}\frac{d \tau}{\tau} \\ \frac{d \mu_{s}}{\mu_{s}+(1+c) A} \\ \frac{d \mu_{u}}{\mu_{u}+(1+c) A}\end{array}\right]$

and after calculations:

$$
\begin{gathered}
\frac{d S}{S}=\frac{M_{S \tau}}{\Delta} \frac{d \tau}{\tau}+\frac{M_{S S}}{\Delta} \frac{d \mu_{s}}{\mu_{s}+(1+c) A}+\frac{M_{S U}}{\Delta} \frac{d \mu_{u}}{\mu_{u}+(1+c) A} \\
\frac{d U^{*}}{U^{*}}=\frac{M_{U \tau}}{\Delta} \frac{d \tau}{\tau}+\frac{M_{U S}}{\Delta} \frac{d \mu_{s}}{\mu_{s}+(1+c) A}+\frac{M_{U U}}{\Delta} \frac{d \mu_{u}}{\mu_{u}+(1+c) A}
\end{gathered}
$$

where, using the equalities $A_{K}=A_{S}+\frac{K}{\bar{K}-K} A_{U}$ and $A_{S}-A_{U}=1-\beta$ :

$$
\begin{aligned}
M_{S \tau} & =\frac{\bar{K}-K}{\bar{K}} B_{K}+B_{U}+\beta \frac{\bar{K}-K}{\bar{K}}=\frac{\bar{K}-K}{\bar{K}}\left(B_{K}+\beta\right)+B_{U} \\
M_{S S} & =\left(\frac{\bar{K}-K}{\bar{K}} B_{K}+B_{U}\right)\left(\frac{\bar{K}-K}{\beta \bar{K}} A_{K}-\frac{K}{\bar{K}}\right)-\frac{\bar{K}-K}{\bar{K}}\left(\frac{\bar{K}-K}{\beta \bar{K}} B_{K}-A_{S}\right) \\
& =\frac{\bar{K}-K}{\beta \bar{K}}\left\{\left[\frac{\bar{K}-K}{\bar{K}} A_{K}+(1-\beta) \frac{K}{\bar{K}}-1\right] B_{K}+\beta A_{S}+\left(A_{K}-\frac{\beta K}{\bar{K}-K}\right) B_{U}\right\} \\
& =\frac{\bar{K}-K}{\beta \bar{K}}\left[\left(A_{S}-1\right) B_{K}+\beta A_{S}+\left(A_{K}-\frac{\beta K}{\bar{K}-K}\right) B_{U}\right] \\
M_{S U} & =-\frac{\bar{K}-K}{\beta \bar{K}}\left(A_{K}+\beta\right)\left(\frac{\bar{K}-K}{\bar{K}} B_{K}+B_{U}\right)-\frac{\bar{K}-K}{\bar{K}}\left(A_{U}-\frac{\bar{K}-K}{\beta \bar{K}} B_{K}\right) \\
& =-\frac{\bar{K}-K}{\beta \bar{K}}\left[\left(A_{K}+\beta-1\right) \frac{\bar{K}-K}{\bar{K}} B_{K}+\left(A_{K}+\beta\right) B_{U}+\beta A_{U}\right] \\
& =-\frac{\bar{K}-K}{\beta \bar{K}}\left[\left(B_{K}+\beta\right) A_{U}+\left(A_{K}+\beta\right) B_{U}\right]
\end{aligned}
$$

and:

$$
\begin{aligned}
M_{U \tau} & =\frac{\bar{K}-K}{\bar{K}} B_{K}-B_{S}-\beta \frac{K}{\bar{K}} \\
M_{U S} & =\left(\frac{\bar{K}-K}{\bar{K}} B_{K}-B_{S}\right)\left(\frac{\bar{K}-K}{\beta \bar{K}} A_{K}-\frac{K}{\bar{K}}\right)+\frac{K}{\bar{K}}\left(\frac{\bar{K}-K}{\beta \bar{K}} B_{K}-A_{S}\right) \\
& =\frac{\bar{K}-K}{\beta \bar{K}}\left[\left(\frac{\bar{K}-K}{\bar{K}} B_{K}-B_{S}\right)\left(A_{K}-\frac{\beta K}{\bar{K}-K}\right)+\frac{K}{\bar{K}}\left(B_{K}-\frac{\beta \bar{K}}{\bar{K}-K} A_{S}\right)\right] \\
& =\frac{\bar{K}-K}{\beta \bar{K}}\left[A_{S} B_{K}-A_{K} B_{S}+\frac{\beta K}{\bar{K}-K}\left(B_{S}-A_{S}\right)\right] \\
M_{U U} & =-\frac{\bar{K}-K}{\beta \bar{K}}\left(A_{K}+\beta\right)\left(\frac{\bar{K}-K}{\bar{K}} B_{K}-B_{S}\right)+\frac{K}{\bar{K}}\left(A_{U}-\frac{\bar{K}-K}{\beta \bar{K}} B_{K}\right) \\
& =\frac{K}{\bar{K}} A_{U}-\frac{\bar{K}-K}{\beta \bar{K}}\left\{\left[\left(A_{K}+\beta\right) \frac{\bar{K}-K}{\bar{K}}+\frac{K}{\bar{K}}\right] B_{K}-\left(A_{K}+\beta\right) B_{S}\right\} \\
& =\frac{\bar{K}-K}{\beta \bar{K}}\left[\left(A_{K}+\beta\right) B_{S}-\left(A_{U}+1\right) B_{K}+\frac{\beta K}{\bar{K}-K} A_{U}\right]
\end{aligned}
$$


Combining the two expressions, we get:

$$
\frac{d S}{S}-\frac{d U^{*}}{U^{*}}=\frac{D_{\tau}}{\Delta} \frac{d \tau}{\tau}+\frac{D_{S}}{\Delta} \frac{d \mu_{s}}{\mu_{s}+(1+c) A}+\frac{D_{U}}{\Delta} \frac{d \mu_{u}}{\mu_{u}+(1+c) A}
$$

where:

$$
\begin{aligned}
D_{\tau} & =M_{S \tau}-M_{U \tau}=B_{U}+B_{S}+\beta \\
D_{S} & =M_{S S}-M_{U S}=\left(\frac{\bar{K}-K}{\beta \bar{K}} A_{K}-\frac{K}{\bar{K}}\right)\left(B_{U}+B_{S}\right)-\frac{\bar{K}-K}{\beta \bar{K}} B_{K}+A_{S} \\
D_{U} & =M_{S U}-M_{U U}=-\frac{\bar{K}-K}{\beta \bar{K}}\left[\left(A_{K}+\beta\right)\left(B_{U}+B_{S}\right)-B_{K}\right]-A_{U}
\end{aligned}
$$

hence:

$$
\begin{aligned}
\frac{d K}{K}= & \frac{\bar{K}-K}{\bar{K}}\left(\frac{d S}{S}-\frac{d U^{*}}{U^{*}}\right)+\frac{\bar{K}-K}{\beta \bar{K}}\left[\frac{d \mu_{s}}{\mu_{s}+(1+c) A}-\frac{d \mu_{u}}{\mu_{u}+(1+c) A}\right] \\
= & \frac{\bar{K}-K}{\bar{K}}\left[\frac{D_{\tau}}{\Delta} \frac{d \tau}{\tau}+\frac{D_{S}}{\Delta} \frac{d \mu_{s}}{\mu_{s}+(1+c) A}+\frac{D_{U}}{\Delta} \frac{d \mu_{u}}{\mu_{u}+(1+c) A}\right] \\
& +\frac{\bar{K}-K}{\beta \bar{K}}\left[\frac{d \mu_{s}}{\mu_{s}+(1+c) A}-\frac{d \mu_{u}}{\mu_{u}+(1+c) A}\right] \\
= & \frac{\bar{K}-K}{\bar{K} \Delta} D_{\tau} \frac{d \tau}{\tau}+\frac{\bar{K}-K}{\beta \bar{K}}\left(1+\frac{\beta D_{S}}{\Delta}\right) \frac{d \mu_{s}}{\mu_{s}+(1+c) A}+\frac{\bar{K}-K}{\beta \bar{K}}\left(\frac{\beta D_{U}}{\Delta}-1\right) \frac{d \mu_{u}}{\mu_{u}+(1+c) A}
\end{aligned}
$$

Knowing that $A_{K}=A_{S}+\frac{K}{\bar{K}-K} A_{U}, A_{S}-A_{U}=1-\beta, A_{K}>0, A_{S}>0, A_{U}>0, B_{K}<0$, $B_{S}>0, B_{U}>0$, and $\frac{U^{*}}{\bar{K}-K}<\frac{S}{K}$, we find the following signs:

$$
\begin{aligned}
\Delta= & \frac{\bar{K}-K}{\bar{K}}\left(B_{K}-B_{S}\right)+\frac{K}{\bar{K}} B_{U} \\
= & \frac{\bar{K}-K}{\bar{K}}\left[-\frac{\tau K / p}{Q_{2}+Q_{2}^{*}}-\frac{A(1+c)}{Q_{1}+Q_{1}^{*}} S-\frac{(1-\beta) Q_{2}}{Q_{2}+Q_{2}^{*}}\right] \\
& +\frac{K}{\bar{K}}\left[\frac{A(1+c)}{Q_{1}+Q_{1}^{*}} U^{*}+\frac{(1-\beta) Q_{2}^{*}}{Q_{2}+Q_{2}^{*}}\right] \\
= & -\frac{K(\bar{K}-K)}{\bar{K}}\left[\frac{\tau / p}{Q_{2}+Q_{2}^{*}}+\frac{A(1+c)}{Q_{1}+Q_{1}^{*}}\left(\frac{S}{K}-\frac{U^{*}}{\bar{K}-K}\right)+\frac{1-\beta}{Q_{2}+Q_{2}^{*}}\left(\frac{Q_{2}}{K}-\frac{Q_{2}^{*}}{\bar{K}-K}\right)\right]<0
\end{aligned}
$$

and:

$$
B_{K}+\beta=\frac{\bar{K}}{\bar{K}-K} \frac{\beta Q_{2}^{*}}{Q_{2}+Q_{2}^{*}}>0
$$

so that:

$$
\begin{aligned}
M_{S \tau} & =\frac{\bar{K}-K}{\bar{K}}\left(B_{K}+\beta\right)+B_{U}=\frac{\beta Q_{2}^{*}}{Q_{2}+Q_{2}^{*}}+B_{U}>0 \\
M_{U \tau} & =\frac{\bar{K}-K}{\bar{K}} B_{K}-B_{S}-\beta \frac{K}{\bar{K}}<0 \\
M_{S U} & =-\frac{\bar{K}-K}{\beta \bar{K}}\left[\left(B_{K}+\beta\right) A_{U}+\left(A_{K}+\beta\right) B_{U}\right]<0 \\
M_{U U} & =\frac{\bar{K}-K}{\beta \bar{K}}\left[\left(A_{K}+\beta\right) B_{S}-\left(A_{U}+1\right) B_{K}+\frac{\beta K}{\bar{K}-K} A_{U}\right]>0 \\
D_{\tau} & =B_{U}+B_{S}+\beta>0
\end{aligned}
$$


and:

$$
\begin{aligned}
\beta D_{U}-\Delta & =\frac{\bar{K}-K}{\bar{K}}\left[B_{K}-\left(A_{K}+\beta\right)\left(B_{U}+B_{S}\right)\right]-\beta A_{U}-\frac{\bar{K}-K}{\bar{K}}\left(B_{K}-B_{S}\right)-\frac{K}{\bar{K}} B_{U} \\
& =\frac{\bar{K}-K}{\bar{K}} B_{S}-\frac{K}{\bar{K}} B_{U}-\frac{\bar{K}-K}{\bar{K}}\left(A_{K}+\beta\right)\left(B_{U}+B_{S}\right)-\beta A_{U} \\
& =\frac{\bar{K}-K}{\bar{K}}\left(B_{S}+B_{U}\right)-B_{U}-\frac{\bar{K}-K}{\bar{K}}\left(A_{K}+\beta\right)\left(B_{U}+B_{S}\right)-\beta A_{U} \\
& =-\frac{\bar{K}-K}{\bar{K}}\left(A_{K}+\beta-1\right)\left(B_{U}+B_{S}\right)-\beta A_{U}-B_{U} \\
& =-A_{U}\left(B_{U}+B_{S}+\beta\right)-B_{U}<0
\end{aligned}
$$

The signs of the following coefficients have not been determined yet:

$$
\begin{aligned}
M_{S S} & =\frac{\bar{K}-K}{\beta \bar{K}}\left[\left(A_{S}-1\right) B_{K}+\beta A_{S}+\left(A_{K}-\frac{\beta K}{\bar{K}-K}\right) B_{U}\right] \\
M_{U S} & =\frac{\bar{K}-K}{\beta \bar{K}}\left[A_{S} B_{K}-A_{K} B_{S}+\frac{\beta K}{\bar{K}-K}\left(B_{S}-A_{S}\right)\right] \\
\beta D_{S}+\Delta & =\left(\frac{\bar{K}-K}{\bar{K}} A_{K}-\beta \frac{K}{\bar{K}}\right)\left(B_{U}+B_{S}\right)-\frac{\bar{K}-K}{\bar{K}} B_{S}+\frac{K}{\bar{K}} B_{U}+\beta A_{S} \\
& =\left[\frac{\bar{K}-K}{\bar{K}} A_{K}+(1-\beta) \frac{K}{\bar{K}}\right] B_{U}+\left(\frac{\bar{K}-K}{\bar{K}} A_{K}-\beta \frac{K}{\bar{K}}-\frac{\bar{K}-K}{\bar{K}}\right) B_{S}+\beta A_{S} \\
& =\left[\frac{\bar{K}-K}{\bar{K}} A_{K}+(1-\beta) \frac{K}{\bar{K}}\right] B_{U}+\left[\frac{\bar{K}-K}{\bar{K}} A_{K}+(1-\beta) \frac{K}{\bar{K}}-1\right] B_{S}+\beta A_{S} \\
& =\left[\frac{\bar{K}-K}{\bar{K}} A_{K}+(1-\beta) \frac{K}{\bar{K}}\right] B_{U}+\left(A_{S}-1\right) B_{S}+\beta A_{S}
\end{aligned}
$$

To summarize, we get the following results:

$$
\begin{aligned}
\frac{d S}{S} & =\frac{M_{S \tau}}{\Delta} \frac{d \tau}{\tau}+\frac{M_{S S}}{\Delta} \frac{d \mu_{s}}{\mu_{s}+(1+c) A}+\frac{M_{S U}}{\Delta} \frac{d \mu_{u}}{\mu_{u}+(1+c) A} \\
\frac{d U^{*}}{U^{*}} & =\frac{M_{U \tau}}{\Delta} \frac{d \tau}{\tau}+\frac{M_{U S}}{\Delta} \frac{d \mu_{s}}{\mu_{s}+(1+c) A}+\frac{M_{U U}}{\Delta} \frac{d \mu_{u}}{\mu_{u}+(1+c) A} \\
\frac{d K}{K} & =\frac{\bar{K}-K}{\bar{K} \Delta} D_{\tau} \frac{d \tau}{\tau}+\frac{\bar{K}-K}{\beta \bar{K}}\left(1+\frac{\beta D_{S}}{\Delta}\right) \frac{d \mu_{s}}{\mu_{s}+(1+c) A}+\frac{\bar{K}-K}{\beta \bar{K}}\left(\frac{\beta D_{U}}{\Delta}-1\right) \frac{d \mu_{u}}{\mu_{u}+(1+c) A}
\end{aligned}
$$

with $\Delta<0, M_{S \tau}>0, M_{U \tau}<0, M_{S U}>0, M_{U U}>0, D_{\tau}>0, \beta D_{U}-\Delta<0$, so that:

\begin{tabular}{c|cc} 
& $\frac{d \tau}{\tau}$ & $\frac{d \mu_{u}}{\mu_{u}+(1+c) A}$ \\
\hline$\frac{d K}{K}$ & - & + \\
$\frac{d S}{S}$ & - & + \\
$\frac{d U^{*}}{U^{*}}$ & + & -
\end{tabular}




\section{A.4 Impact of a risk premium and a migration cost variation on the factor allocation (small transfer case)}

Let us look at the impact of a change in the risk premium and the unskilled migration cost on the factor allocation among countries, for a small investment to the South (case developed in Section 4.4).

Let us remind the equilibrium equations:

$$
\begin{aligned}
\tau & =\beta B p\left\{\left[\frac{(1-\beta) B p}{(1+c) A}\right]^{\frac{1}{\beta}-1}-\left(\frac{U^{*}}{\bar{K}-K}\right)^{1-\beta}\right\}=\beta p\left(\frac{Q_{2}}{K}-\frac{Q_{2}^{*}}{\bar{K}-K}\right) \\
\mu_{u} & =(1-\beta) p B\left(\frac{\bar{K}-K}{U^{*}}\right)^{\beta}-(1+c) A=(1-\beta) p \frac{Q_{2}^{*}}{U^{*}}-(1+c) A
\end{aligned}
$$

The logarithmic derivatives of these equilibrium conditions are:

$$
\begin{aligned}
\frac{d \tau}{\tau} & =\frac{d p}{p}+\frac{d\left\{\left[\frac{(1-\beta) B p}{(1+c) A}\right]^{\frac{1}{\beta}-1}-\left(\frac{U^{*}}{K-K}\right)^{1-\beta}\right\}}{\left[\frac{(1-\beta) B p}{(1+c) A}\right]^{\frac{1}{\beta}-1}-\left(\frac{U^{*}}{K-K}\right)^{1-\beta}} \\
& =\frac{d p}{p}+\frac{\left(\frac{1}{\beta}-1\right)\left[\frac{(1-\beta) B p}{(1+c) A}\right]^{\frac{1}{\beta}-1} \frac{d p}{p}-(1-\beta)\left(\frac{U^{*}}{\bar{K}-K}\right)^{1-\beta}\left(\frac{d U^{*}}{U^{*}}+\frac{d K}{K-K}\right)}{\left[\frac{(1-\beta) B p}{(1+c) A}\right]^{\frac{1}{\beta}-1}-\left(\frac{U^{*}}{K-K}\right)^{1-\beta}} \\
& =\left\{1+\frac{\left(\frac{1}{\beta}-1\right)\left[\frac{(1-\beta) B p}{(1+c) A}\right]^{\frac{1}{\beta}-1}}{\left[\frac{(1-\beta) B p}{(1+c) A}\right]^{\frac{1}{\beta}-1}-\left(\frac{U^{*}}{K-K}\right)^{1-\beta}}\right\} \frac{d p}{p}-\frac{(1-\beta)\left(\frac{U^{*}}{\bar{K}-K}\right)^{1-\beta}}{\left[\frac{(1-\beta) B p}{(1+c) A}\right]^{\frac{1}{\beta}-1}-\left(\frac{U^{*}}{K-K}\right)^{1-\beta}}\left(\frac{d U^{*}}{U^{*}}+\frac{d K}{\bar{K}-K}\right) \\
\frac{d \mu_{u}}{\mu_{u}+(1+c) A} & =\frac{d p}{p}-\beta\left(\frac{d K}{\bar{K}-K}+\frac{d U^{*}}{U^{*}}\right)
\end{aligned}
$$

which may be written as:

$$
\begin{aligned}
\frac{d \tau}{\tau} & =\left(1+\beta^{-1} D\right) \frac{d p}{p}-C\left(\frac{d U^{*}}{U^{*}}+\frac{K}{\bar{K}-K} \frac{d K}{K}\right) \\
\frac{d \mu_{u}}{\mu_{u}+(1+c) A} & =\frac{d p}{p}-\beta\left(\frac{K}{\bar{K}-K} \frac{d K}{K}+\frac{d U^{*}}{U^{*}}\right)
\end{aligned}
$$

where:

$$
\begin{aligned}
C & =\frac{(1-\beta)\left(\frac{U^{*}}{K-K}\right)^{1-\beta}}{\left[\frac{(1-\beta) B p}{(1+c) A}\right]^{\frac{1}{\beta}-1}-\left(\frac{U^{*}}{K-K}\right)^{1-\beta}}=(1-\beta) \frac{\beta B p}{\tau}\left(\frac{U^{*}}{\bar{K}-K}\right)^{1-\beta}>0 \\
D & =\frac{(1-\beta)\left[\frac{(1-\beta) B p}{(1+c) A}\right]^{\frac{1}{\beta}-1}}{\left[\frac{(1-\beta) B p}{(1+c) A}\right]^{\frac{1}{\beta}-1}-\left(\frac{U^{*}}{\bar{K}-K}\right)^{1-\beta}}=(1-\beta) \frac{\beta B p}{\tau}\left[\frac{(1-\beta) B p}{(1+c) A}\right]^{\frac{1-\beta}{\beta}}>0 \\
D-C & =1-\beta
\end{aligned}
$$


As there is no explicit solution for the price, we use the total derivative of the equilibrium condition:

$$
(1-\gamma) A\left[U+c\left(\bar{S}-U^{*}\right)\right]=(1-\beta+\beta \gamma) p Q_{2}+\gamma p Q_{2}^{*}
$$

with the logarithmic derivatives of the outputs:

$$
\begin{aligned}
& Q_{2}=K B^{\frac{1}{\beta}}\left[\frac{(1-\beta) p}{(1+c) A}\right]^{\frac{1}{\beta}-1} \Longrightarrow \frac{d Q_{2}}{Q_{2}}=\frac{d K}{K}+\left(\frac{1}{\beta}-1\right) \frac{d p}{p} \\
& Q_{2}^{*}=B(\bar{K}-K)^{\beta}\left(U^{*}\right)^{1-\beta} \Longrightarrow \frac{d Q_{2}^{*}}{Q_{2}^{*}}=-\beta \frac{K}{\bar{K}-K} \frac{d K}{K}+(1-\beta) \frac{d U^{*}}{U^{*}}
\end{aligned}
$$

to get an expression of $d p / p$ :

$$
\begin{aligned}
-(1-\gamma) A(1+c) U^{*} \frac{d U^{*}}{U^{*}}= & (1-\beta+\beta \gamma) p Q_{2}\left(\frac{d p}{p}+\frac{d Q_{2}}{Q_{2}}\right)+\gamma p Q_{2}^{*}\left(\frac{d p}{p}+\frac{d Q_{2}^{*}}{Q_{2}^{*}}\right) \\
= & (1-\beta+\beta \gamma) p Q_{2}\left(\frac{d K}{K}+\frac{1}{\beta} \frac{d p}{p}\right)+\gamma p Q_{2}^{*}\left[\frac{d p}{p}-\beta \frac{K}{\bar{K}-K} \frac{d K}{K}+(1-\beta) \frac{d U^{*}}{U^{*}}\right] \\
= & \left(\frac{1-\beta+\beta \gamma}{\beta} Q_{2}+\gamma Q_{2}^{*}\right) p \frac{d p}{p}+\left[(1-\beta+\beta \gamma) Q_{2}-\beta \gamma Q_{2}^{*} \frac{K}{\bar{K}-K}\right] p \frac{d K}{K} \\
& +(1-\beta) \gamma p Q_{2}^{*} \frac{d U^{*}}{U^{*}} \\
\Leftrightarrow \frac{d p}{p}= & -\frac{(1-\beta+\beta \gamma) Q_{2}-\beta \gamma Q_{2}^{*} \frac{K}{K-K}}{\frac{1-\beta+\beta \gamma}{\beta} Q_{2}+\gamma Q_{2}^{*}} \frac{d K}{K}-\frac{(1-\beta) \gamma p Q_{2}^{*}+(1-\gamma) A(1+c) U^{*}}{\left(\frac{1-\beta+\beta \gamma}{\beta} Q_{2}+\gamma Q_{2}^{*}\right) p} \frac{d U^{*}}{U^{*}} \\
= & -E_{K} \frac{d K}{K}-E_{U} \frac{d U^{*}}{U^{*}}
\end{aligned}
$$

where:

$$
\begin{aligned}
& E_{K}=\frac{(1-\beta+\beta \gamma) Q_{2}-\beta \gamma Q_{2}^{*} \frac{K}{K-K}}{\frac{1-\beta+\beta \gamma}{\beta} Q_{2}+\gamma Q_{2}^{*}}=\frac{(1-\beta) Q_{2}+\beta \gamma K\left(\frac{Q_{2}}{K}-\frac{Q_{2}^{*}}{\bar{K}-K}\right)}{\frac{1-\beta+\beta \gamma}{\beta} Q_{2}+\gamma Q_{2}^{*}}>0 \\
& E_{U}=\frac{(1-\beta) \gamma p Q_{2}^{*}+(1-\gamma) A(1+c) U^{*}}{\left(\frac{1-\beta+\beta \gamma}{\beta} Q_{2}+\gamma Q_{2}^{*}\right) p}>0
\end{aligned}
$$

the positive sign of $E_{K}$ coming from the small investment condition (24).

Then:

$$
\begin{aligned}
\frac{d \tau}{\tau} & =-\left(1+\beta^{-1} D\right)\left(E_{K} \frac{d K}{K}+E_{U} \frac{d U^{*}}{U^{*}}\right)-C\left(\frac{d U^{*}}{U^{*}}+\frac{K}{\bar{K}-K} \frac{d K}{K}\right) \\
& =-\left[\left(1+\beta^{-1} D\right) E_{K}+C \frac{K}{\bar{K}-K}\right] \frac{d K}{K}-\left[\left(1+\beta^{-1} D\right) E_{U}+C\right] \frac{d U^{*}}{U^{*}} \\
\frac{d \mu_{u}}{\mu_{u}+(1+c) A} & =-E_{K} \frac{d K}{K}-E_{U} \frac{d U^{*}}{U^{*}}-\beta\left(\frac{K}{\bar{K}-K} \frac{d K}{K}+\frac{d U^{*}}{U^{*}}\right) \\
& =-\left(E_{K}+\frac{\beta K}{\bar{K}-K}\right) \frac{d K}{K}-\left(E_{U}+\beta\right) \frac{d U^{*}}{U^{*}}
\end{aligned}
$$

which may be written as:

$$
M\left[\begin{array}{c}
\frac{d K}{K} \\
\frac{d U^{*}}{U^{*}}
\end{array}\right]=-\left[\begin{array}{c}
\frac{d \tau}{\tau} \\
\frac{d \mu_{u}}{\mu_{u}+(1+c) A}
\end{array}\right]
$$


where:

$$
M=\left[\begin{array}{cc}
\left(1+\beta^{-1} D\right) E_{K}+C \frac{K}{\bar{K}-K} & \left(1+\beta^{-1} D\right) E_{U}+C \\
E_{K}+\frac{\beta K}{\bar{K}-K} & E_{U}+\beta
\end{array}\right]
$$

so that:

$$
\left[\begin{array}{c}
\frac{d K}{K} \\
\frac{d U^{*}}{U^{*}}
\end{array}\right]=-\frac{1}{\Delta} M^{C}\left[\begin{array}{c}
\frac{d \tau}{\tau} \\
\frac{d \mu_{u}}{\mu_{u}+(1+c) A}
\end{array}\right]
$$

where $\Delta$ is the determinant of $M$ :

$$
\begin{aligned}
\Delta & =\left[\left(1+\beta^{-1} D\right) E_{K}+C \frac{K}{\bar{K}-K}\right]\left(E_{U}+\beta\right)-\left(E_{K}+\frac{\beta K}{\bar{K}-K}\right)\left[\left(1+\beta^{-1} D\right) E_{U}+C\right] \\
& =(\beta+D-C)\left(E_{K}-\frac{K}{\bar{K}-K} E_{U}\right)=E_{K}-\frac{K}{\bar{K}-K} E_{U}
\end{aligned}
$$

and $M^{C}$ is the co-factors matrix:

$$
M^{C}=\left[\begin{array}{cc}
E_{U}+\beta & -\left(1+\beta^{-1} D\right) E_{U}-C \\
-\left(E_{K}+\frac{\beta K}{K-K}\right) & \left(1+\beta^{-1} D\right) E_{K}+C \frac{K}{K-K}
\end{array}\right]
$$

Using the expressions for $E_{K}$ and $E_{U}$, we get:

$$
\Delta=E_{K}-\frac{K}{\bar{K}-K} E_{U}=\frac{(1-\beta+\beta \gamma) p \frac{Q_{2}}{K}-\gamma p \frac{Q_{2}^{*}}{\bar{K}-K}-(1-\gamma) A(1+c) \frac{U^{*}}{\bar{K}-K}}{\left(\frac{1-\beta+\beta \gamma}{\beta} Q_{2}+\gamma Q_{2}^{*}\right) p K^{-1}}
$$

The denominator of $\Delta$ is straightforwardly positive. As for the numerator, using the equilibrium conditions, we get:

$$
\begin{aligned}
\text { Num } & =(1-\beta+\beta \gamma) p \frac{Q_{2}}{K}-\gamma p \frac{Q_{2}^{*}}{\bar{K}-K}-(1-\gamma) A(1+c) \frac{U^{*}}{\bar{K}-K} \\
& =(1-\beta+\beta \gamma) p \frac{Q_{2}}{K}-\gamma p \frac{Q_{2}^{*}}{\bar{K}-K}-(1-\gamma) \frac{U^{*}}{\bar{K}-K}\left[(1-\beta) p \frac{Q_{2}^{*}}{U^{*}}-\mu_{u}\right] \\
& =(1-\beta+\beta \gamma) p \frac{Q_{2}}{K}-[\gamma+(1-\gamma)(1-\beta)] p \frac{Q_{2}^{*}}{\bar{K}-K}+(1-\gamma) \frac{\mu_{u} U^{*}}{\bar{K}-K} \\
& =(1-\beta+\beta \gamma) p\left(\frac{Q_{2}}{K}-\frac{Q_{2}^{*}}{\bar{K}-K}\right)+(1-\gamma) \frac{\mu_{u} U^{*}}{\bar{K}-K} \\
& =\frac{1-\beta+\beta \gamma}{\beta} \tau+\frac{(1-\gamma) K}{\bar{K}-K} \mu_{u} U^{*}>0
\end{aligned}
$$

so that $\Delta>0$.

Then, the diagonal terms of $M^{C}$ being unambiguously positive and the two non diagonal terms unambiguously negative, we get the following signs for the impacts of an increase in $\tau$ and $\mu_{u}$ :

\begin{tabular}{c|cc} 
& $\frac{d \tau}{\tau}$ & $\frac{d \mu_{u}}{\mu_{u}+(1+c) A}$ \\
\hline$\frac{d K}{K}$ & - & + \\
$\frac{d U^{*}}{U^{*}}$ & + & -
\end{tabular}

